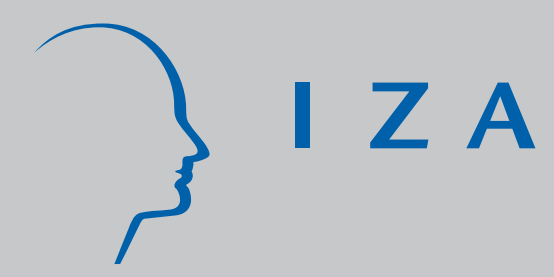

IZA DP No. 2747

Brain Drain, Fiscal Competition, and Public Education Expenditure

\author{
Hartmut Egger \\ J osef Falkinger \\ Volker Grossmann
}

April 2007 


\title{
Brain Drain, Fiscal Competition, and Public Education Expenditure
}

\author{
Hartmut Egger \\ University of Zurich, \\ CESifo and GEP \\ Josef Falkinger \\ University of Zurich, \\ CESifo and IZA \\ Volker Grossmann \\ University of Fribourg, \\ CESifo and IZA
}

Discussion Paper No. 2747

April 2007

IZA
P.O. Box 7240
53072 Bonn
Germany

Phone: +49-228-3894-0

Fax: +49-228-3894-180

E-mail: iza@iza.org

\begin{abstract}
Any opinions expressed here are those of the author(s) and not those of the institute. Research disseminated by IZA may include views on policy, but the institute itself takes no institutional policy positions.

The Institute for the Study of Labor (IZA) in Bonn is a local and virtual international research center and a place of communication between science, politics and business. IZA is an independent nonprofit company supported by Deutsche Post World Net. The center is associated with the University of Bonn and offers a stimulating research environment through its research networks, research support, and visitors and doctoral programs. IZA engages in (i) original and internationally competitive research in all fields of labor economics, (ii) development of policy concepts, and (iii) dissemination of research results and concepts to the interested public.
\end{abstract}

IZA Discussion Papers often represent preliminary work and are circulated to encourage discussion. Citation of such a paper should account for its provisional character. A revised version may be available directly from the author. 


\section{ABSTRACT}

\section{Brain Drain, Fiscal Competition, and Public Education Expenditure}

This paper uses a two-country model with integrated markets for high-skilled labor to analyze the opportunities and incentives for national governments to provide higher education. Countries can differ in productivity, and education is financed through a wage tax, so that brain drain affects the tax base and has agglomeration effects. We study unilateral possibilities for triggering or avoiding brain drain and compare education policies and migration patterns in non-cooperative political equilibria with the consequences of bilateral cooperation between countries. We thereby demonstrate that bilateral coordination tends to increase public education expenditure compared to non-cooperation. At the same time, it aims at preventing migration. This is not necessarily desirable from the point of view of a social planner who takes account of the interests of migrants.

JEL Classification: F22, H52

Keywords: brain drain, educational choice, public education policy, locational competition

Corresponding author:

Josef Falkinger

Socioeconomic Institute

University of Zurich

Zurichbergstr. 14

$\mathrm{CH}-8032$ Zurich

Switzerland

E-mail: josef.falkinger@wwi.unizh.ch

\footnotetext{
* We are grateful to Stephanie Bade, Nicole Brändle, and Markus Regez for excellent research assistance. We also acknowledge valuable comments by David Stadelmann, Fabrizio Zilibotti, Josef Zweimüller, and participants at the conference on "Immigration: Impacts, Integration and Intergenerational Issues" held at University College London in 2006.
} 


\section{Introduction}

The long-standing debate on the implications of the international migration of educated workers has recently intensified. In the United States, the share of foreign-born persons among the college educated increased from 7.3 to 15 percent between 1980 and 2000 (Bound and Turner, 2006). In Canada, Australia, and Switzerland, more than 25 percent of residents with tertiary education was foreign born in 2000 (OECD, 2006a; Tab. I.7). By contrast, despite positive net inflow of educated workers from developing countries, some OECD countries are experiencing a significant net brain drain, particularly the eastern European countries and Mexico, but also Finland, Germany, and Italy. ${ }^{1}$

In view of widespread public financing of education throughout the world, ${ }^{2}$ international migration of high-skilled labor has revived the debate on fiscal competition. Indeed, fiscal losses from brain drain can be severe (Lucas, 2005, Ch. 4), and they are a potential source of conflict in the process of economic integration. The Council of Europe (1995) therefore recommends that in order to "strengthen higher education and [...] diminish the risk of brain drain, countries are strongly encouraged to [...] develop structured programmes of European and regional, bilateral and multilateral cooperation at government level." (This recommendation was renewed in 2000.)

On the basis of a two-country model, and allowing for productivity differences between countries, this paper examines the implications of fiscal competition and bilateral cooperation for publicly financed education under mobility of high-skilled labor and endogenous educational choice. Whereas the countries may differ in the model as regards total factor productivity, education technologies, individual learning costs, and relative demand for high-skilled labor are assumed to be identical. This simplification allows us to isolate the strategic role of tax and education policies from other causes of brain drain.

\footnotetext{
${ }^{1}$ In 2000, for instance, (the stock of) net emigration of high-skilled workers amounted to 11.9 and 7.6 percent, respectively, of all highly educated residents in the Slovak Republic and Poland. For Finland and Germany, the figures were 4.6 and 3.9 percent, respectively (OECD, 2006a; Tab. I.7). Becker, Ichino, and Peri (2004) document a dramatic increase in the brain drain from Italy during the 1990s.

${ }^{2}$ According to the OECD (2006b, Tab B3.1, Tab. B3.2b), the average share of total education expenditure by public institutions within the OECD was 88 percent for all education levels and 76.4 percent for tertiary institutions in the year 2003 .
} 
(The simplification seems innocuous if brain drain between OECD countries - rather than brain drain in a North-South context - is considered.) Public education expenditure is financed by a wage tax. Migrants face costs when they leave their home country to work abroad, so that emigration becomes attractive only if the foreign net wage is sufficiently high compared to the domestic net wage. ${ }^{3}$ Brain drain has fiscal externalities because it affects the tax base in the source and the receiver country. This gives rise to agglomeration effects and potential multiplicity of equilibria for given education policies. In the case of multiple equilibria, the migration pattern depends on the beliefs of mobile highskilled workers. Two types of beliefs are distinguished in our analysis - a "stay-home" and a "go-abroad" belief. In the first case, high-skilled workers stay in their home country whenever this is consistent with rational behavior. In the second case, workers migrate, although non-migration would also be consistent with rational behavior.

We first analyze how possible equilibrium migration patterns depend on the migration costs of high-skilled workers and on public expenditure policy. Second, we examine policy actions, assuming that national governments base their decisions on the welfare of non-migrants. We distinguish between non-sophisticated and rational (or sophisticated) governments. A non-sophisticated government takes the pattern of migration as given and chooses the optimal level of education expenditure in accordance with the assumed pattern of migration, taking into account the educational decisions of individuals. Rational governments additionally consider the possibility of actively changing the pattern of brain drain in their favor. In this context, we introduce the concept of a "deviation cone." Roughly speaking, this is the set of policy actions that induce a change in the pattern of migration and are welfare-enhancing from a national point of view - as compared to the equilibrium in the game between non-sophisticated governments. If the incentives for changing the migration pattern are sufficiently strong, non-cooperative political equilibria may not exist, in particular when migration costs are low. In this case, there is an ongoing struggle between countries for educated workers.

\footnotetext{
${ }^{3}$ The fact that wage differentials are an important incentive for high-skilled workers to migrate is empirically well supported (see, e.g., Beine, Docquier, and Rapoport, 2001; Lucas, 2005).
} 
In a non-cooperative equilibrium without migration, there is no role for bilateral coordination. If non-cooperative policy-setting leads to an equilibrium with brain drain, education expenditure is inefficiently low. This is not surprising in view of the fiscal externalities. However, we show that from the perspective of a utilitarian social planner, bilateral coordination of education policies does not necessarily solve the problem. On the one hand, bilateral coordination tends to increase public education expenditure compared to the non-cooperative levels. On the other hand, however, bilaterally coordinated policies are based on the welfare of non-migrants, whereas the social planner also considers the utility of migrants. This has consequences for the desired migration pattern. While coordination favors non-migration, the social planner may prefer brain drain in order to extract migration gains. In fact, an endeavor to stop migration through a bilateral contract may even reduce welfare compared to a non-cooperative equilibrium.

The remainder of the paper is organized as follows. Section 2 discusses related literature. Section 3 presents the model. Section 4 analyzes the equilibrium for a given public education policy. In Section 5, we examine how governments have to adjust their education expenditure in order to avoid brain drain when labor market integration reduces migration costs for high-skilled workers. Section 6 analyzes the policy games of both non-sophsticated and rational governments. The consequences of cooperation between governments for public education expenditure, welfare, and migration patterns are examined in Section 7. The last section presents our conclusions.

\section{Related Literature}

Rather than attempting to provide an exhaustive overview of the voluminous literature on the consequences of international mobility of high-skilled labor, this section highlights the relevance and contribution of our paper to the debate on fiscal policy under the threat or existence of brain drain. This relates our paper to a strand of the literature that is concerned with the implications of brain drain for the tax system (see, e.g., Bhagwati and Wilson, 1989). For instance, there is the much-debated proposal of an emigration tax, 
designed to mitigate the adverse consequences of brain drain for the source country (e.g., Bhagwati and Dellalfar, 1973; Bhagwati and Hamada, 1974). ${ }^{4}$ More recently, Poutvaara (2004a) has argued that due to fiscal externalities arising from international migration of high-skilled labor, the member states of the European Union should also be allowed to collect graduate taxes from emigrants so as to finance education. The analysis in Poutvaara (2004b) points to an efficiency-enhancing role for graduate taxes when labor mobility provides incentives for governments to gear public education toward countryspecific rather than internationally applicable education. Our analysis is complementary to this strand of literature. Rather than exploring how governments should react to brain drain by reforming the tax system, we study fiscal competition through public education expenditure under a given tax system.

Another related strand of the literature deals with tax competition in the context of human capital formation. Wildasin (2000) and Poutvaara and Kanniainen (2000) show that under perfect mobility of high-skilled labor, tax competition drives down the tax rate of high-skilled labor to zero in a small open economy. ${ }^{5}$ In contrast to these papers, we analyze competition through public education expenditure between two large economies under imperfect mobility of high-skilled labor. Andersson and Konrad (2003) argue that tax competition between Leviathan governments that is induced by migration possibilities for the educated has ambiguous effects on welfare. On the one hand, it curbs excessive taxation but, on the other, it provides incentives for governments to prevent individuals from investing in education. Rather than analyzing Leviathan behavior, we consider benevolent governments that maximize the welfare of non-migrants.

\footnotetext{
${ }^{4}$ Bucovetsky (2003) focuses on the effects of migration on optimal redistribution across states in a federation. Assuming that migration toward rich states is efficient, he argues that the local tax system should become more progressive in response to declining migration costs. In a context of credit constraints and the administrative costs of taxation, Haupt and Janeba (2004) also show that redistribution to poorer individuals possibly should increase when the market for high-skilled labor becomes more integrated.

${ }^{5}$ According to Wildasin (2000), this provides a rationale to shift the balance in the education system away from public, and toward private financing. He argues that under private education financing, the mobility of high-skilled labor is efficiency-enhancing because it provides insurance against idiosyncratic risk across regions with specific human capital investment. Poutvaara and Kanniainen (2000) consider a framework where low-ability workers are willing to subsidize the education of high-ability workers in a closed economy if there are positive externalities of acquiring education. However, the mobility of high-skilled labor makes such a social contract infeasible.
} 
Closest to our work, Justman and Thisse (1997, 2000) show that mobility of highskilled labor typically leads to under-provision of public education finance. As in our paper, the tax system is given. ${ }^{6}$ However, there are also important differences. For instance, Justman and Thisse abstract from differences in the economic fundamentals of countries and do not account for possible agglomeration effects. Thus, as common in the existing literature on fiscal competition with mobile high-skilled labor, they focus on symmetric equilibria. However, as concluded by Justman and Thisse (2000, p. 255) in their discussion of potential future work, "the most interesting problems may arise in asymmetric cases." In our model, countries may differ in total factor productivity, and we demonstrate that this asymmetry has important implications for migration patterns with and without fiscal competition. Furthermore, we account for agglomeration effects due to changes in the tax base when high-skilled workers migrate. These agglomeration effects may give rise to asymmetric equilibria even if countries do not differ in their economic fundamentals. Our setting also allows us to address interesting questions related to cooperation among governments that are facing the threat of brain drain. Like the analysis of asymmetric equilibria, policy coordination has been neglected in the brain drain literature.

\section{The Model}

Consider two open economies indexed $H$ and $F$ ("home" and "foreign") with two types of labor. High-skilled workers (at least a certain share of them) are mobile and look for the best income possibilities in the two economies. In contrast, the labor markets for low-skilled workers are internationally segmented. ${ }^{7}$ The two types of labor are used to manufacture a single homogenous (numéraire) good. Output $Y^{j}$ in country $j$ is produced

\footnotetext{
${ }^{6}$ Whereas these authors assume a property tax, in our model public education is financed by a proportional wage tax.

${ }^{7}$ That low-skilled workers are immobile is the standard assumption in the brain drain literature. For evidence of the impact of education on the propensity and intention to migrate, see, e.g., Uebelmesser (2006) and the references therein.
} 
according to

$$
Y^{j}=F^{j}\left(S^{j}, L^{j}\right)=A^{j}\left(S^{j}\right)^{\beta}\left(L^{j}\right)^{1-\beta}
$$

where $A^{j}>0$ and $\beta \in(0,1) . S^{j}, L^{j}$ are efficiency units of high-skilled and low-skilled labor in $j=H, F . A^{j}$ denotes total factor productivity in country $j$.

There is a unit mass of workers, indexed $i \in[0,1]$, who make two decisions: first, whether or not to acquire higher education; and, second, if high-skilled, whether or not to migrate to the other country. Individuals take the migration decision into account when deciding whether or not to acquire education. That is, individuals are aware of earning opportunities abroad as well as at home. They are endowed with one unit of time. Acquisition of education requires $\bar{e} \in[0,1)$ units of time, so that $1-\bar{e}$ is the residual working time of an educated individual.

Utility of an individual $i$ living at home is simply given by the level of consumption, $C(i)$. However, following a standard assumption in the literature (e.g., Stark, Hehnenstein, and Prskawetz, 1997), living abroad implies that utility is given by a discounted value of consumption which, for example, reflects the social costs of living in a foreign environment. Formally, the utility of migrant $i$ is given by $C(i) /(1+\theta a(i))$, where $a(i)=1$ for a mass $q \in(0,1)$ of high-skilled workers and $a(i)=\bar{a}>1$ for the rest of them. To exclude the (unrealistic) possibility of migration of all high-skilled workers, suppose that $\bar{a}$ is prohibitively high. ${ }^{8}$ Moreover, assume that an individual who is indifferent as regards leaving and staying (at home) does not migrate. Parameter $\theta$ reflects the degree of international integration. A decline in $\theta$ means a more mobile high-skilled labor force.

An individual without higher education supplies one efficiency unit of low-skilled labor, so that employment $L^{j}$ is equal to the mass of low-skilled workers in country $j$. The efficiency units of high-skilled labor supplied by an educated worker depend on the quality of the education system. This is one important channel through which policy affects brain drain. Let $G^{j}, j=H, F$ be the level of public expenditure to promote higher education.

\footnotetext{
${ }^{8}$ Restricting the analysis to two types of individuals with respect to migration costs greatly simplifies the analysis. However, the main insights from our analysis would remain the same if more than two types of individuals were taken into account. The assumption that $q<1$ guarantees that the mass of educated workers is higher than the mass of high-skilled emigrants.
} 
We assume that the acquired level of qualification increases with $G^{j}$. More specifically, an individual born in country $j$ acquires $G^{j}$ units of high-skilled labor if he/she chooses education. Let $s^{j}=1-L^{j}$ denote the mass of educated workers and $\mu^{H}$ denote the mass of high-skilled workers educated in $H$ who migrate to country $F$, while $\mu^{F}$ is the mass of high-skilled workers migrating from $F$ to $H$. Then the total amount of efficiency units of high-skilled labor employed in country $j=H, F$ is given by ${ }^{9}$

$$
S^{j}=(1-\bar{e})\left[\left(1-L^{j}-\mu^{j}\right) G^{j}+\mu^{k} G^{k}\right], k \neq j .
$$

The education system in $j$ produces $(1-\bar{e})\left(1-L^{j}\right) G^{j}$ units of high-skilled labor. $(1-\bar{e}) \mu^{j} G^{j}$ are lost through brain drain from $j$ to $k$ and $(1-\bar{e}) \mu^{k} G^{k}$ come from inflow of high-skilled workers educated abroad.

\section{Equilibrium Patterns of Brain Drain}

In this section the economic equilibrium is determined. Education policies $G^{H}, G^{F}$ are exogenously given.

Let $w_{S}^{j}$ and $w_{L}^{j}$ denote country $j$ 's wage rate per efficiency unit of high-skilled and low-skilled labor, respectively. Education is financed by a wage income tax. Suppose that workers live where they work, in other words, residence-based and source-based labor income taxation is equivalent. For the sake of simplicity, the tax is proportional, with tax rate $\tau^{j} \in[0,1)$ in country $j=H, F$. Then, observing the cost of time $\bar{e}$ to acquire education, the consumption of a native individual from $H$ is given by

$$
C^{H}= \begin{cases}(1-\bar{e})\left(1-\tau^{H}\right) w_{S}^{H} G^{H} & \text { if high skilled and working in } H \\ (1-\bar{e})\left(1-\tau^{F}\right) w_{S}^{F} G^{H} & \text { if high skilled and working in } F \\ \left(1-\tau^{H}\right) w_{L}^{H} & \text { if low skilled. }\end{cases}
$$

A worker who stays in her/his country of birth must be indifferent as to the choice

\footnotetext{
${ }^{9}$ Recall that $1-\bar{e}$ is the residual working time of an educated individual.
} 
between acquiring education or remaining low skilled in equilibrium. According to (3), this implies that

$$
\phi \equiv \frac{1}{1-\bar{e}}=\omega^{H} G^{H}
$$

where $\omega^{H} \equiv w_{S}^{H} / w_{L}^{H}$ is the relative wage rate of high-skilled to low-skilled labor in country $H$ in terms of efficiency units. ${ }^{10}$ Note that because individuals do not differ in ability, relative wage income $\omega^{H} G^{H} / \phi$ is a constant and equal to one, while $\omega^{H}$ declines if the education system provides a higher skill level $G^{H}$ or the time costs of education $\bar{e}$ diminish. For the migration decision of high-skilled individuals, consumption level $(1-\bar{e})\left(1-\tau^{H}\right) w_{S}^{H} G^{H}$ when staying at home has to be compared with the discounted consumption level when migrating, $(1-\bar{e})\left(1-\tau^{F}\right) w_{S}^{F} G^{H} /(1+\theta) .{ }^{11}$ A highskilled worker born and educated in $H$ moves to $F$ if and only if

$$
1+\theta<\frac{\left(1-\tau^{F}\right) w_{S}^{F}}{\left(1-\tau^{H}\right) w_{S}^{H}}
$$

Because of migration costs, income earned in $F$ is discounted by $1+\theta$. Migration is attractive if the net wage advantage of working in $F$ rather than in $H$ covers this discount. Condition (5) implies that migration can go only in one direction. Thus, either $\mu^{H} \geq 0$ and $\mu^{F}=0$, or $\mu^{H}=0$ and $\mu^{F} \geq 0$ in the following analysis. ${ }^{12}$

Lemma 1 The net wage in country $j=H, F$ is positive if

$$
G^{j}<\bar{G}^{j}\left(\mu^{j}\right) \equiv\left(\frac{1-\mu^{j}}{\phi^{\beta}} b A^{j}\right)^{\frac{1}{1-\beta}}
$$

\footnotetext{
${ }^{10}$ If $\omega^{H} G^{H}<\phi$, we have a corner solution where nobody in $H$ chooses higher education. By assuming (4), we exclude the case of countries with zero higher education from the analytical discussion. However, the numerical analysis accounts for corner solutions. In particular, we check whether zero higher education could be a reasonable policy from a social planner's point of view.

${ }^{11}$ Use (3) and recall that $1+\theta$ is the discount rate of the mobile group of high-skilled workers. The other group has prohibitively high mobility costs.

${ }^{12}$ In a recent contribution, Schmitt and Soubeyran (2006) investigate the phenomenon of brain circulation (i.e., two-way high-skilled migration flows) in a model where high-skilled individuals differ in their talents and human capital is exogenous. In our analysis, there is only one type of high-skilled labor, so brain circulation cannot occur.
} 
Moreover, for $\mu^{H} \geq 0, \mu^{F}=0$, the relative net wage is given by:

$$
\frac{\left(1-\tau^{F}\right) w_{S}^{F}}{\left(1-\tau^{H}\right) w_{S}^{H}}=\frac{b A^{F}\left(\phi / G^{F}\right)^{1-\beta}-\phi /\left[1+\mu^{H} G^{H} / G^{F}\right]}{b A^{H}\left(\phi / G^{H}\right)^{1-\beta}-\phi /\left[1-\mu^{H}\right]} \equiv \chi^{H}\left(\mu^{H}\right) .
$$

\section{Proof. See Appendix A.}

The feasible level of education expenditure is limited by the country's total factor productivity and its domestic labor force. The further analysis assumes that condition (6) is satisfied. $\chi^{H}\left(\mu^{H}\right)$ represents the incentives to migrate from $H$ to $F$, which - according to $(5)$ - have to be compared with the cost $1+\theta$. For $\mu^{H}=0, \mu^{F} \geq 0$, an analogous expression $\chi^{F}\left(\mu^{F}\right)$ describes the incentives to migrate from $F$ to $H$.

If there is brain drain from $H$ to $F$, that is, if $\mu^{H}>0$ and $\mu^{F}=0$, then the tax revenue per efficiency unit of high-skilled labor $\left(\tau^{j} w_{S}^{j}\right)$ rises from $\phi$ to $\phi /\left(1-\mu^{H}\right)$. This increases the incentives of high-skilled workers to leave $H$. Thus, the tax channel generates agglomeration effects in favor of the receiver country. The tax payment per efficiency unit of high-skilled labor in $F$ is $\phi /\left(1+\mu^{H} G^{H} / G^{F}\right)$. Inflow $\mu^{H}$ of high-skilled labor from $H$ broadens F's tax base so that the tax burden per individual declines. This reinforces the agglomeration effect. The tax advantage in the receiver country is all the stronger the better are the qualifications of incoming workers because under income taxation the tax contribution of immigrants increases with their skill level.

Figure 1 shows $\chi^{H}\left(\mu^{H}\right)$ and $\chi^{F}\left(\mu^{F}\right)$ for given levels of productivity and education expenditure. Without loss of generality, $G^{H} / G^{F} \geq\left(A^{H} / A^{F}\right)^{1 /(1-\beta)}$ is assumed. (Note that the roles of $H$ and $F$ can be changed in the following discussion.) $\chi^{H}\left(\mu^{H}\right)$ is an increasing function of $\mu^{H}$, which starts at

$$
\chi^{H}(0)=\frac{b A^{F}\left(\phi / G^{F}\right)^{1-\beta}-\phi}{b A^{H}\left(\phi / G^{H}\right)^{1-\beta}-\phi} \geq 1,
$$

and goes to infinity as $\mu^{H}$ approaches $m^{H} \equiv 1-\phi^{\beta}\left(G^{H}\right)^{1-\beta} /\left(b A^{H}\right)$. Function $\chi^{F}\left(\mu^{F}\right)$ starts at $\chi^{F}(0)=1 / \chi^{H}(0)>0$ and approaches infinity as $\mu^{F}$ approaches $m^{F} \equiv 1-$ $\phi^{\beta}\left(G^{F}\right)^{1-\beta} /\left(b A^{F}\right)$. The economic reason why migration incentives $\chi^{j}$ rise with $\mu^{j}$ are 
the agglomeration advantages coming from the tax channel. At $m^{j}, j=H, F$, brain drain would erode $j$ 's tax base so that financing $G^{j}$ would become unfeasible. Condition (6) restricts the analysis to feasible education levels, which implies $\mu^{j} \leq q<m^{j}$ in equilibrium.

\section{$>$ Figure $1<$}

Comparing the returns to migration to the cost of working in a foreign country, we see that the following patterns of brain drain hold in equilibrium. If migration costs are high $\left(1+\theta^{\prime \prime}\right.$ in Figure 1), then $\chi^{j}\left(\mu^{j}\right) \leq \chi^{j}(q)<1+\theta^{\prime \prime}$ for all $\mu^{j} \leq q$. Thus, according to (5), no educated worker will leave his/her home country and only non-migration can hold in equilibrium in this case. At cost $1+\theta^{\prime}$, non-migration is still an equilibrium since $\chi^{F}(0)<\chi^{H}(0)<1+\theta^{\prime}$. However, $\tilde{B}^{H}$ and $B^{H}$ are also equilibria. At $\tilde{\mu}^{H}$, individuals are indifferent as to whether they will work abroad or in their home country. But any deviation to the left eliminates migration $\left(\chi^{H}\left(\mu^{H}\right)<1+\theta^{\prime}\right.$ for $\left.\mu^{H}<\tilde{\mu}^{H}\right)$, whereas any deviation to the right induces more migration $\left(\chi^{H}\left(\mu^{H}\right)>1+\theta^{\prime}\right.$ for $\left.\mu^{H}>\tilde{\mu}^{H}\right)$. We call such an equilibrium unstable. In contrast, $B^{H}$ is a stable equilibrium since $\chi^{H}(q)>1+\theta^{\prime}$ and all mobile workers have gone from $H$ to $F$. If migration costs diminish further, migration from $F$ to $H$ can also be an equilibrium. For instance, at cost $1+\theta$, we have an unstable equilibrium $\tilde{B}^{F}$ and a stable equilibrium $B^{F}$, in addition to equilibrium $B^{H}{ }^{13}$ Throughout the following analysis, we focus on the stable equilibria, that is, either $\mu^{H}=\mu^{F}=0, \mu^{H}=q$, or $\mu^{F}=q .^{14}$

The multiplicity of equilibria reflects a general feature of international factor markets under agglomeration effects. Here, the agglomeration effect stems from the fact that outflows of high-skilled workers make it harder to finance public education, while inflows

\footnotetext{
${ }^{13}$ In the interest of simplicity, we assumed that the share of mobile workers among the high skilled is the same in both countries. It is easy to examine the consequences of $q^{H} \neq q^{F}$ in Figure 1. The principal arguments and conclusions are not influenced by this modification.

${ }^{14} \mathrm{An}$ unstable economic equilibrium is not consistent with an optimal policy choice. To see this, assume that for given $G^{j}$ and $G^{k}$ levels, the two economies end up in an unstable equilibrium like $\tilde{\mu}^{j}>0$ in Figure 1. Then a marginal reduction of $G^{j}$ would induce a significant inflow of mobile high-skilled workers to country $j$, which would increase the utility of the workers in country $j$. Hence, we can safely ignore unstable equilibria in the subsequent analysis.
} 
make it easier. In the next section, we examine for given education policies $G^{H}, G^{F}$ whether a non-migration equilibrium can be sustained when international labor markets for high-skilled workers become more integrated. We also explain how we deal with policy combinations that give rise to multiple migration equilibria. To be more specific, we introduce a selection criterion that allows us to characterize optimal non-cooperative education policies in Section 6.

\section{Opening up the Labor Market for the High-Skilled - How Much Scope for Education Policy?}

Suppose that up to now, high-skilled workers have worked where they were educated. As in Figure 1, let $\chi^{F}(0)<\chi^{H}(0)$. Now suppose migration costs decline from $\theta^{\prime \prime}$ to $\theta$ (such that $\left.\chi^{H}(0)>1+\theta>\chi^{F}(0)\right)$. In this case, domestic education policy is too ambitious relative to total factor productivity and mobile high-skilled workers of country $H$ benefit from leaving their home county and working abroad. The resulting brain drain from $H$ to $F$ has detrimental consequences for immobile workers in $H$, whose tax burden increases. Therefore, a crucial question facing national policymakers is how education expenditure can be adjusted in order to prevent this brain drain.

If $\theta$ approaches zero, an outcome without migration is feasible only if countries $H$ and $F$ choose their policies in such a way that $\chi^{H}(0)=\chi^{F}(0)=1$. In this case, locations $H$ and $F$ are equally attractive for high-skilled workers. According to (7), this requires $G^{H} / G^{F}=\left(A^{H} / A^{F}\right)^{1 /(1-\beta)}$. In Figure 2, line $E A$ with slope $\left(A^{H} / A^{F}\right)^{1 /(1-\beta)}$ represents the locus of equal attractiveness.

$>$ Figure $2<$

An outcome with $\mu^{H}=0$ requires $1+\theta \geq \chi^{H}(0)$. This gives us the following constraint: ${ }^{15}$

$$
G^{H} / G^{F} \leq \rho_{0}^{H}\left(A^{H} / A^{F}\right)^{\frac{1}{1-\beta}}
$$

\footnotetext{
${ }^{15}$ Solve $\chi^{H}(0) \leq 1+\theta$ for $G^{H}$, where $\chi^{H}(0)$ is given by (8), and divide the resulting expression by $G^{F}$.
} 
with

$$
\rho_{0}^{H} \equiv\left[\frac{1+\theta}{1+\theta \phi^{\beta}\left(G^{F}\right)^{1-\beta} /\left(b A^{F}\right)}\right]^{\frac{1}{1-\beta}} .
$$

Condition (9) defines the set of policy combinations that are consistent with $\mu^{H}=0$. The bound of this set is the incentive constraint for non-migration, represented by $I_{0}^{H}$ in Figure 2. ${ }^{16}$ Policy combinations on line $I_{0}^{H}$ fulfill the condition that $\chi^{H}(0)=1+\theta$ and, therefore, render mobile high-skilled workers indifferent as to whether they should stay at home or work abroad. $\rho_{0}^{H}$ describes country $H$ 's scope for $\mu^{H}=0$ supporting policy. When $\theta$ declines, the scope for raising education expenditure above the $E A$ line narrows. ${ }^{17}$ If $\theta=0$, then $I_{0}^{H}$ coincides with the $E A$ line, so that country $H$ 's scope for education policies that support $\mu^{H}=0$ is bounded by the productivity differential. To determine which policy combinations are consistent with $\mu^{F}=0$, we have added locus $I_{0}^{F}$ in Figure 2. $\left(I_{0}^{F}\right.$ is defined by an analogous condition to (9) with $\rho_{0}^{F}$ increasing in $\theta$. Hence, $I_{0}^{F}$ lies in the region below the $E A$ line.) The set of policy combinations that are consistent with non-migration is bounded by $I_{0}^{H}$ and $I_{0}^{F}$.

But do governments really succeed in preventing brain drain by choosing policy combinations in the lens bounded by $I_{0}^{H}$ and $I_{0}^{F}$ ? We know from Figure 1 that - due to the agglomeration effects of brain drain - the equilibrium migration pattern is not necessarily unique. This implies that certain policy combinations in the lens bounded by the two incentive constraints $I_{0}^{H}$ and $I_{0}^{F}$, although consistent with non-migration, may be consistent with brain drain too, say from $H$ to $F$. To determine the policy domain associated with multiple migration patterns, we consider the constraint for policy combinations that prevent brain drain from $H$ to $F$. This constraint is given by $\chi^{H}(q) \geq 1+\theta$. Analogously to $(9)$, it can be written in the form

$$
G^{H} / G^{F} \leq \rho_{1}^{H}\left(A^{H} / A^{F}\right)^{\frac{1}{1-\beta}}
$$

\footnotetext{
${ }^{16}$ The position and shape of $I_{0}^{H}$ result from the following facts: First, according to $(6),\left(G^{F}\right)^{1-\beta}<$ $b A^{F} / \phi^{\beta}$. Thus, for $\theta>0, \rho_{0}^{H}>1$ and $I_{0}^{H}$ lies above the $E A$ line. Second, as $G^{F}$ increases, $\rho_{0}^{H}$ decreases from $(1+\theta)^{1 /(1-\beta)}$, for $G^{F}=0$, to one, for $G^{F}=\bar{G}^{F}(0)$ (use (6)). This explains the concave shape of $I_{0}^{H}$.

${ }^{17}$ Use $\phi^{\beta}\left(G^{F}\right)^{1-\beta} /\left(b A^{F}\right)<1$ from (6).
} 
where for any $G^{F}, \rho_{1}^{H}<\rho_{0}^{H}$ and $\partial \rho_{1}^{H} / \partial \theta>0$ (see Appendix B). The upper bound of policy combinations preventing brain drain from $H$ to $F$ is represented by the curve $I_{H \rightarrow F}$ in Figure 2. ${ }^{18}$ Since $\rho_{1}^{H}<\rho_{0}^{H}$, the incentive constraint $I_{H \rightarrow F}$ lies below the incentive constraint $I_{0}^{H}$. Only relatively strong expenditure and tax cuts in the source country can outweigh the agglomeration advantages of the receiver country. Like $I_{0}^{H}$, the incentive constraint $I_{H \rightarrow F}$ rotates downward when migration costs decline: $\partial \rho_{1}^{H} / \partial \theta>0$. (To avoid clutter, the respective constraint $I_{F \rightarrow H}$, which gives a lower bound to policy combinations preventing brain drain from $F$ to $H$, is not depicted in Figure 2.)

Policy pairs in the region bounded by $I_{0}^{H}$ and $I_{H \rightarrow F}$ are associated with multiple migration patterns. This multiplicity of migration equilibria constitutes a problem for the characterization of optimal non-cooperative education policies in Section 6. The reason is that national governments base their expenditure decisions on certain expectations concerning the equilibrium migration pattern. However, it is not clear how these expectations are formed if multiple migration patterns are possible. To overcome this problem, we introduce a selection criterion that is based on a publicly known (and identical) belief of mobile high-skilled workers about the equilibrium $\left(\mu^{H}, \mu^{F}\right)$ pattern.

As the baseline, we assume that for policy combinations in the northwest of constraint $I_{0}^{H}$, mobile high-skilled workers base their migration decisions on the belief of $\mu^{H}=$ $q, \mu^{F}=0$, while, for policy combinations in the southeast of $I_{0}^{F}$, migration behavior is based on the belief of $\mu^{H}=0, \mu^{F}=q$. Finally, for policy combinations in the lens bounded by the two incentive constraints $I_{0}^{H}, I_{0}^{F}$, the belief is one of non-migration. We use the term "stay-home beliefs" to refer to this baseline scenario. Under stay-home beliefs, mobile high-skilled workers do not migrate whenever an outcome with $\mu^{H}=\mu^{F}=0$ is consistent with rational behavior. In this case, the previous analysis provides us with the following important insights: If a country prefers not to educate people who work abroad after education, then the country should bring its public education expenditure into line with the scope defined by (9). This scope is narrowed when $\theta$ decreases.

\footnotetext{
${ }^{18}$ The position and shape of $I_{H \rightarrow F}$ result from $\rho_{1}^{H}<\rho_{0}^{H}$ and the following facts, which are derived in Appendix B. First, for $\theta>0, \rho_{1}^{H}>1$ at $G^{F}=0$, implying that $I_{H \rightarrow F}$ lies above the $E A$ line for low $G^{F}$. Second, $\rho_{1}^{H}$ is decreasing in $G^{F}$, which explains the concave shape of $I_{H \rightarrow F}$.
} 
In addition to the baseline case of stay-home beliefs, we also consider the alternative case that migration decisions are based on the belief of $\mu^{H}=q, \mu^{F}=0$, if a policy combination in the northwest of incentive constraint $I_{H \rightarrow F}$ (instead of constraint $\left.I_{0}^{H}\right)$ is realized. (In all other respects we maintain the assumptions of the baseline scenario.) We use the term "go-abroad beliefs" to refer to this alternative scenario. Under go-abroad beliefs, mobile high-skilled workers migrate from $H$ to $F$ whenever $\mu^{H}=q, \mu^{F}=0$ is consistent with rational behavior. In this case, mobile high-skilled workers of country $H$ anticipate the agglomeration effects of migration and the scope for policies avoiding brain drain from $H$ to $F$ shrinks from $\rho_{0}^{H}$ to $\rho_{1}^{H}$, that is, (10) instead of (9) becomes the relevant constraint.

So far the interaction of education policy and brain drain has been analyzed at a positive level. In the next section, we turn to the normative question as to how a country should use its scope for policy.

\section{Optimal Education Policies from a National Point of View}

When international labor markets for high-skilled workers are opened up, three policy scenarios are of interest from the perspective of a national government. First, the government is satisfied with non-migration and focuses on education levels that avoid brain drain. Second, it accepts that high-skilled workers will migrate to the other country and adapts education expenditure optimally to the expected brain drain. Finally, it tries to attract high-skilled workers from abroad by cutting education expenditure and taxes. Under the first two scenarios, governments are not fully rational because they do not consider using education and tax policy for changing the pattern of brain drain in their

favor. We call such policies "non-sophisticated" policies as opposed to rational ones, and we characterize non-cooperative education policies of both non-sophisticated and rational governments. For this purpose, we have to specify the national policy goal. 
A unilateral increase in public education expenditure $G^{j}$ not only increases labor productivity in $j$, but also the gains of high-skilled workers in $j$ from moving to $k \neq j$. Since workers who leave $j$ do not bear the tax cost of education expenditure in their home country, they benefit unambiguously from generous education policy. However, for national governments the workers who stay are decisive, because it may reasonably be assumed that the median voter does not migrate. Therefore, we look at the impact of $G^{j}$ on the low-skilled workers and on the high-skilled workers who work in $j$.

By virtue of (3) and (4), the consumption levels of the low-skilled and the nonmigrating high-skilled workers are identical and given by net wage $W^{j} \equiv\left(1-\tau^{j}\right) w_{L}^{j}$. Thus, we can take $W^{j}$ as an objective function of the government.

Lemma 2 The net wage of residents in $j$ is given by

$$
W^{j}=b A^{j}\left(G^{j} / \phi\right)^{\beta}-\frac{G^{j}}{\left[1-\mu^{j}+\mu^{k} G^{k} / G^{j}\right]}, \quad j \neq k \in\{H, F\} .
$$

For any given $\mu^{j}, \mu^{k} \in[0, q]$, objective function $W^{j}$ has a unique maximum at $\tilde{G}^{j}\left(\mu^{j}, \mu^{k} ; G^{k}\right)$ $>0, j \neq k$. We have (i) $\partial \tilde{G}^{j} / \partial \mu^{j}<0$, (ii) $\partial \tilde{G}^{j} / \partial \mu^{k}>0$, and (iii) $\partial \tilde{G}^{j} / \partial G^{k}>0$ if $\mu^{k}>0$, else $\partial \tilde{G}^{j} / \partial G^{k}=0$. Moreover, (iv) $\tilde{G}^{j}\left(0,0, G^{k}\right)=\left(\beta b A^{j} / \phi^{\beta}\right)^{1 /(1-\beta)}$.

Proof. See Appendix A.

For any given migration pattern, Lemma 2 characterizes $j$ 's best reply to policy $G^{k}$. We use the following notation: $G_{0}^{j}$ denotes $j$ 's best reply function conditional on nonmigration, while $G_{j \rightarrow k}^{j}$ is $j$ 's best reply function conditional on brain drain from $j$ to $k$. However, the best reply functions determined in Lemma 2 are not necessarily consistent with the incentive constraints of mobile high-skilled workers. If an incentive constraint is binding, education expenditure has to be adjusted in order to sustain the assumed migration pattern. This points to the role played by the scope for policy when determining behavior of non-sophisticated governments in the following subsection. 


\subsection{Non-Sophisticated Policy Responses}

Let us first consider the case of stay-home beliefs. The best reply of country $j$ conditional on $\mu^{H}=\mu^{F}=0$ is given by $G_{0}^{j}=\left(\beta b A^{j} / \phi^{\beta}\right)^{1 /(1-\beta)}$. The two best replies $G_{0}^{H}, G_{0}^{F}$ intersect on line $E A$ - the locus of equal attractiveness - within the incentive constraints $I_{0}^{H}, I_{0}^{F}$ for non-migration. Hence, with $G_{0}^{H}, G_{0}^{F}$ the governments sustain an equilibrium without brain drain. In particular, if countries choose optimal education policies before international labor market integration, non-sophisticated governments do not change their policies and no brain drain is triggered when labor markets for high-skilled workers are opened up (even if $\theta$ declines to zero). In Figure $3, G_{0}^{H}$ and $G_{0}^{F}$ describe the best-reply functions conditional on $\mu^{H}=\mu^{F}=0$. Under stay-home beliefs, the set of policy combinations consistent with non-migration is given by the lens between $I_{0}^{H}$ and $I_{0}^{F}$ in Figure 2. Hence, the best reply functions are truncated. $N_{0}$ in Figure 3 is the resulting Nash equilibrium.

\section{$>$ Figure $3<$}

What happens if governments expect migration from $H$ to $F$ and accommodate this brain drain? According to Part (iii) of Lemma 2, H's best reply, conditional on brain drain from $H$ to $F$, is still inelastic with respect to $G^{F}$. However, according to Part (i), $G^{H}$ is reduced compared to the conditional Nash equilibrium without migration. In

Figure 3, this conditional best reply is represented by $G_{H \rightarrow F}^{H}$. In contrast to $H$, for the receiver country $F$, education expenditure $G^{F}$ is a strategic complement to expenditure $G^{H}$ (Lemma 2 (iii)). The inflow of high-skilled workers broadens the tax base of country $F$. This makes it easier to promote education, and country $F$ chooses $G_{H \rightarrow F}^{F}$ if this is consistent with migration pattern $\mu^{H}=q, \mu^{F}=0$. The point of intersection $N_{1}$ between $H$ 's best reply $G_{H \rightarrow F}^{H}$ and $F$ 's best reply $G_{H \rightarrow F}^{F}$ is a candidate for a non-cooperative policy equilibrium conditional on the assumption that educated workers migrate from $H$ to $F$. But are these policies consistent with the assumed pattern of brain drain? Since point $N_{1}$ lies southeast of $N_{0}$, it certainly lies below the incentive constraint $I_{0}^{H}$, even if migration costs vanish. Hence, $N_{1}$ will not trigger brain drain from $H$ to $F$. Therefore, country $F$ has to cut its education expenditure in order to sustain the assumed migration pattern. 
Under stay-home beliefs, $N_{1}^{\prime}$ defines the maximal $G^{F}$ level that is consistent with brain drain from $H$ to $F$, if country $H$ sets $G_{H \rightarrow F}^{H} \cdot{ }^{19}$

Let us now consider the case of go-abroad beliefs. In this case, the outcome of nonmigration is preserved if intersection point $N_{0}$ lies below the relevant $I_{H \rightarrow F}$ curve. If, however, $N_{0}$ lies above the constraint $I_{H \rightarrow F}$, country $H$ can avoid an outflow of highskilled workers only if it brings its education expenditure into line with the scope defined by (10). In Figure 3, depending on the level of migration costs, the maximal $G^{H}$ level that avoids brain drain from $H$ to $F$ is defined by $N_{0}^{\prime}$ (for $\theta_{1}$ ) or $N_{0}^{\prime \prime}$ (for $\theta_{2}$ ), respectively, if country $F$ sets $G_{0}^{F}$. By contrast, an equilibrium with brain drain from $H$ to $F$ requires that education policies lie above constraint $I_{H \rightarrow F}$. Figure 3 again shows two cases. Case 1: If the cost of working in a foreign country is low $\left(\theta_{1}\right)$, then $N_{1}$ is consistent with incentive constraint $I_{H \rightarrow F}$ and thus supports brain drain from $H$ to $F$. Case 2: If the cost of working abroad is high $\left(\theta_{2}\right)$, then incentive constraint $I_{H \rightarrow F}$ lies above $N_{1}$, so that at $N_{1}$ there would be no migration or even migration from $F$ to $H$. In view of $G_{H \rightarrow F}^{H}$, country $F$ remains attractive for high-skilled migrants from $H$ only if it cuts education expenditure. $N_{1}^{\prime \prime}$ defines the maximal $G^{F}$ level sustaining brain drain from $H$ to $F$ under go-abroad beliefs. ${ }^{20}$

The insights from this subsection are subject to a big question mark: Is it really reasonable to accept a given pattern of brain drain? Or is there scope for changing the pattern through education policy and should a government avail of that scope?

\subsection{Rational Policies and Nash equilibrium}

A country that attracts high-skilled migrants from abroad benefits from agglomeration advantages. This leaves the following choice for a source country: Either adapt optimally to the given circumstances as analyzed for $H$ in Subsection 6.1, or undercut the optimal education and tax level in order to shift brain drain in your own favor. The costs of

\footnotetext{
${ }^{19}$ Strictly speaking, country $F$ must reduce its expenditure to slightly below the $G^{F}$ level determined by $N_{1}^{\prime}$ if we assume that mobile high-skilled workers from country $H$ stay at home when $\chi^{H}(0) \geq 1+\theta$.

${ }^{20}$ To avoid clutter, we do not show equilibria with brain drain from $F$ to $H$ in Figure 3.
} 
deviating from optimal adaptation as well as the benefits of changing the pattern of migration can be evaluated by comparing the net wage function $W^{j}$ for different $\mu^{j}, \mu^{k}$ constellations.

Figure 4 illustrates for the three possible equilibria identified in Section 4 the objective function $W^{H}$ and the best responses of $H$ to a given foreign education policy. Subscripts $H \rightarrow F, 0, F \rightarrow H$ refer to migration from $H$ to $F$, non-migration, and migration from $F$ to $H$, respectively.

\section{$>$ Figure $4<$}

The ranking $W_{H \rightarrow F}^{H}<W_{0}^{H}<W_{F \rightarrow H}^{H}$ follows from (11), and $G_{H \rightarrow F}^{H}<G_{0}^{H}<G_{F \rightarrow H}^{H}$ follows from Lemma 2. Figure 4 shows that deviation from $G_{0}^{H}$ within range $\left(D_{0}^{H}, G_{0}^{H}\right)$ would be beneficial if such a deviation induced a switch from non-migration to brain drain from $F$ to $H .{ }^{21}$ Analogous bounds $D_{1}^{H}, D_{2}^{H}$ for attractive deviations exist to the left of $G_{H \rightarrow F}^{H}$. If $H$ succeeds in preventing the outflow of high-skilled labor (or even induces inflow from $F$ ) by lowering $G^{H}$ to below $G_{H \rightarrow F}$, this is beneficial as long as $G^{H}$ remains within the range marked by $D_{1}^{H}\left(D_{2}^{H}\right.$, respectively). Since, according to (11), an increase in $G^{F}$ moves the $W^{H}$ curve for $\mu^{H}=0, \mu^{F}=q$ upward, whereas the $W^{H}$ curves for $\left(\mu^{H}, \mu^{F}\right) \in\{(0,0),(q, 0)\}$ are unaffected, $D_{0}^{H}$ and $D_{2}^{H}$ are decreasing in $G^{F}$, while $D_{1}^{H}$ is constant.

This highlights the fact that the non-sophisticated policy reactions described in Subsection 6.1 are only conditional best replies. Within the bound $D^{H}$, a rational government in $H$ is willing to deviate from the conditional best reply if such a deviation changes the migration pattern in its favor. We know from Figure 2 that the equilibrium pattern of migration changes when $G^{H}$ crosses the relevant incentive constraint. A conditional Nash equilibrium, as analyzed in Subsection 6.1, remains an equilibrium under rational policies only if no attractive deviation to a different pattern of migration is feasible. This eliminates all non-sophisticated policies for which incentive constraints of mobile high-skilled

\footnotetext{
${ }^{21}$ We know from the comparative-static analysis that $\chi^{H}$, the net wage rate for high-skilled labor in $F$ relative to the one in $H$, rises if $G^{H}$ is increased (meaning that $F$ becomes more attractive). Thus, it is not possible for $H$ to induce the desired change in the migration pattern by moving to the right of a conditional best response in Figure 4.
} 
workers are binding. Such policies are represented by points $N_{0}^{\prime}, N_{0}^{\prime \prime}, N_{1}^{\prime}$, and $N_{1}^{\prime \prime}$ in Figure 3. If $N_{0}^{\prime}$ or $N_{0}^{\prime \prime}$ is the outcome of non-sophisticated policy setting, then country $F$ induces an inflow of high-skilled labor from country $H$ by marginally reducing $G^{F}$. If the conditional Nash equilibrium is $N_{1}^{\prime}$ or $N_{1}^{\prime \prime}$, then country $H$ can avoid an outflow of high-skilled labor by marginally reducing $G^{H}$. This leaves only two candidates for a Nash equilibrium in the non-cooperative policy game of rational governments: $N_{0}$ and $N_{1}$.

Let us first consider the case of stay-home beliefs. According to the analysis in Subsection 6.1 , only $N_{0}$ is consistent with these beliefs. Figure 5 shows the relevant deviation bound $D_{0}^{H}$ from conditional equilibrium policy $G_{0}^{H}$. (Recall that $D_{0}^{H}$ is decreasing in $G^{F}$.) Deviation successfully triggers brain drain from $F$ to $H$ if incentive constraint $I_{0}^{F}$ is crossed. Thus, the shaded area $D C$ ("deviation cone") to the right of intersection point $T_{0}$ describes the range of deviations from $G_{0}^{H}$ that change the pattern of migration in favor of $H$ and increase $W^{H}$. For high migration costs $\left(\theta_{2}\right)$, there is no policy $G^{H}$ such that $\left(G_{0}^{F}, G^{H}\right) \in D C$. Thus, $H$ will not deviate from $G_{0}^{H}$ and $N_{0}$ is an equilibrium under rational policy setting. However, if migration $\operatorname{cost} \theta$ decreases, incentive constraint $I_{0}^{F}$ moves closer to the $E A$ line. If $\theta$ is sufficiently low $\left(\theta_{1}\right)$, we have an incentive constraint which intersects $D_{0}^{H}$ at a point $\left(T_{0}^{\prime}\right)$ to the left of $G_{0}^{F}$. Then the deviation cone $D C^{\prime}$ contains $\left(G_{0}^{F}, G^{H}\right)$, for some $G^{H}$ and $H$ will deviate from $G_{0}^{H}$. Hence, for sufficiently low migration costs, non-migration cannot be sustained in a Nash equilibrium under rational policy setting.

$>$ Figure $5<$

Under go-abroad beliefs, either $N_{0}$ or $N_{1}$ can be a non-cooperative equilibrium. For $N_{0}$, the deviation incentives are analoguous to the situation discussed for stay-home beliefs. If $N_{1}$ is realized in the game of non-sophisticated governments, then the question is: Will $H$ deviate from conditional best reply $G_{H \rightarrow F}^{H}$ to change the pattern of migration in its favor? If $H$ wants to avoid brain drain from $H$ to $F$, it must cross incentive constraint $I_{H \rightarrow F}$. Figure 6 shows constraints $I_{H \rightarrow F}$ as well as deviation bound $D_{1}^{H}$ (which is constant) for two values of migration $\operatorname{costs} \theta_{1}, \theta_{1}^{\prime}$ with $\theta_{1}^{\prime}<\theta_{1}$. (Both values are low compared to $\theta_{2}$ in 
Figure 3.) While $I_{H \rightarrow F}$ rotates downward when $\theta$ declines, conditional best replies and deviation bounds do not vary with $\theta$.

$>$ Figure $6<$

If migration costs are sufficiently low $\left(\theta_{1}^{\prime}\right)$, country $H$ has no possibility to reach the relevant deviation cone $\left(D C_{1}^{\prime}\right)$ by deviating from $N_{1}=\left(G_{1}^{F}, G_{1}^{H}\right)$. Given that high-skilled migrants suffer a low burden due to working abroad, the expenditure and tax cuts required to prevent migration are too high to be an attractive option for $H$. In contrast, if the burden of working abroad were more severe $\left(\theta_{1}\right)$, then it would be in $H$ 's national interest to induce migrants to stay at home by deviating from $N_{1}$ to $D C_{1}$, that is, by reducing education expenditure. (Apart from avoiding an outflow of high-skilled workers, country $H$ could choose an education policy that leads to reversed brain drain and attracts highskilled workers educated in F. Appendix $\mathrm{C}$ discusses this case.)

In sum, taking into account the incentives of countries to change the pattern of highskilled migration in their favor alters the conclusions based on non-sophisticated policies substantially. We have the following results.

Proposition 1 If governments are rational, then a non-cooperative equilibrium (in pure strategies) may not exist. In particular, if $\theta$ approaches zero, strategic policy setting excludes an equilibrium without migration. Furthermore, an equilibrium with brain drain requires that individual migration decisions are based on go-abroad beliefs.

Proof. Analysis in the text.

The results in Subsection 6.1 and Proposition 1 make clear that the outcome of the noncooperative policy game critically depends on two things: (i) the belief on which workers base their migration decisions, and (ii) the level of sophistication of policymakers. Under stay-home beliefs, for any $\theta$, a non-cooperative equilibrium without migration exists in the game of non-sophisticated governments. In contrast, rational governments attempt to trigger migration if $\theta$ is sufficiently low. They cut taxes and education expenditure in order to attract foreign high-skilled workers. The incentive of governments to lower 
taxes lends support to the idea of a race to the bottom in public education expenditure and may lead to an ongoing struggle for mobile high-skilled workers in our model. The further analysis will show that if a non-cooperative equilibrium with brain drain does exist, then education expenditure will tend to be inefficiently low. ${ }^{22}$ These results point to an important role for international coordination of education policies.

\section{Coordination of National Policies and the Social Planner Solution}

Three questions arise from our analysis of fiscal competition for high-skilled workers: (i) If a Nash equilibrium exists under non-cooperative policy setting, does it result in a satisfactory outcome or can bilateral contracts between national governments achieve coordination gains? (ii) How does coordination affect the pattern of brain drain compared to non-cooperative policies? (iii) Will coordination between national governments lead to an efficient solution?

In view of the possible non-cooperative outcomes, the national governments in $H$ and $F$ ask if there is scope for improving upon the non-cooperative solution by means of coordinated policies. In particular, they examine whether bilateral coordination of public education expenditure paired with transfer payments between the two countries is beneficial for the median voters represented by immobile workers. Coordinated policies are not necessarily optimal from a social planner's point of view because they ignore the gains of high-skilled migrants. We will illustrate this in more detail at the end of the section.

Formally, bilateral coordination means that the two countries $H$ and $F$ agree to choose education policies $G^{H}, G^{F}$ that maximize the sum of the net income levels of the median

\footnotetext{
${ }^{22}$ From Proposition 1 we know that a Nash equilibrium with brain drain and positive education expenditure in both economies requires that the migration decision of mobile high-skilled workers is based on go-abroad beliefs. In our theoretical analysis we have excluded the case of zero national education expenditure (see Footnote 10). If we allowed for corner solutions, a non-cooperative equilibrium with brain drain would also exist under stay-home beliefs. The numerical analysis shows that this is possible if the productivity differential between $H$ and $F$ is sufficiently high.
} 
voters

$$
W^{c} \equiv W^{H}+W^{F}
$$

(rather than $W^{j}, j=H, F$ ) subject to the incentive constraints of mobile workers and subject to the national budget constraints. The main results for coordinated policies are summarized in the following proposition.

Proposition 2 For any given education policies $G^{H}, G^{F}>0, W^{c}$ is higher at $\mu^{j}=\mu^{k}=$ 0 than at $\mu^{j}=q, \mu^{k}=0, j \neq k \in\{H, F\}$. The optimal bilateral contract depends on the beliefs of mobile high-skilled workers. (i) Under stay-home beliefs, the optimal bilateral contract supports non-migration by coordinating on $G_{0}^{H}, G_{0}^{F}$. (ii) Under go-abroad beliefs, policies $G_{0}^{H}, G_{0}^{F}$ are not optimal if migration costs $\theta$ are sufficiently low. In this case, governments may want to coordinate on policies that allow for brain drain. (iii) If noncooperative policy setting of rational governments leads to an equilibrium with brain drain, then coordination increases $W^{c}$ and the direction of brain drain may be reversed.

\section{Proof. See Appendix A.}

The proposition shows that national governments that serve the interests of the workers who stay in their country have a preference for non-migration. The reason is that even though the median voter in the host country of brain drain would gain, this gain is lower than the loss suffered by the median voter in the source country. Therefore, the country threatened by losses from brain drain is willing to pay the other country for not triggering the drain. ${ }^{23}$

According to part (i) of Proposition 2, if mobile high-skilled workers base their migration decision on stay-home beliefs, coordination definitely supports non-migration. This may or may not require signing a contract. If non-migration is also the outcome of noncooperative education policies, there is no role for coordination because the best contract would just reproduce the non-cooperative solution. However, according to Proposition 1,

\footnotetext{
${ }^{23}$ We assume that the transfer payments do not affect the migration decision. In general, redistribution could induce unintended migration so that coordination fails. This can be avoided, for instance, by restricting the payments to immobile workers.
} 
reduced migration costs tend to provoke fiscal competition for foreign high-skilled workers. In this case, bilateral coordination has the role of preventing fiscal competition for high-skilled labor and is definitely in the interest of the national median voters.

If migration decisions are based on go-abroad beliefs, coordinating on $G_{0}^{H}, G_{0}^{F}$ may be less successful in establishing an equilibrium without migration (see the discussion in Subsection 6.1). However, a bilateral contract can stop the possibly ongoing struggle for mobile high-skilled workers under non-cooperative policy setting. Furthermore, if noncooperative policy setting leads to an equilibrium with brain drain from $H$ to $F$, bilateral coordination is definitely beneficial for the national median voters. The coordination may imply education policies that reverse the direction of brain drain, leading to a factor flow from $F$ to $H$. This result may be surprising at first glance because non-migration is the preferred pattern under bilateral coordination. However, non-migration is possibly inconsistent with the optimal bilateral agreements that satisfy the incentive constraints for mobile high-skilled workers.

The bilateral coordination perspective considered here must be clearly distinguished from the social planner solution. National governments care about the utility of median voters but ignore the gains of migrants. In the following, we compare education policies implemented by a utilitarian social planner with the ( $W^{c}$-maximizing) contract resulting from bilateral coordination of education policies.

The social planner chooses education policies in such a way that

$$
S W=W^{c}+\mu^{H} W^{H}\left[\chi^{H} /(1+\theta)-1\right]+\mu^{F} W^{F}\left[\chi^{F} /(1+\theta)-1\right]
$$

is maximized, ${ }^{24}$ subject to the incentive constraints of mobile high-skilled workers and the budget constraints of governments. For given education policies, $S W$ is not necessarily

\footnotetext{
${ }^{24}$ Recall that the utility of non-migrants is given by $C^{j}$, whereas the utility of migrants is $C^{j} /(1+\theta)$. From (3)-(5), $S W=\left(1-\mu^{H}\right) W^{H}+\mu^{H}(1-\bar{e})\left(1-\tau^{F}\right) w_{S}^{F} G^{H} /(1+\theta)+\left(1-\mu^{F}\right) W^{F}+$ $(1-\bar{e})\left(1-\tau^{H}\right) w_{S}^{H} G^{F} /(1+\theta)$, where definition $W^{j}=\left(1-\tau^{j}\right) w_{L}^{j}$ has been used. Expression (13) follows from the definition of $\chi^{H}$ in (7) and the analogous one of $\chi^{F}$, as well as the fact that $W^{j}=(1-\bar{e})\left(1-\tau^{j}\right) w_{S}^{j} G^{j}, j=G, F$, according to (4). Note that either $\mu^{H} \geq 0, \mu^{F}=0$ or $\mu^{H}=0, \mu^{F} \geq 0$.
} 
higher at $\mu^{j}=\mu^{k}=0$ than at $\mu^{j}>0, \mu^{k}=0, j \neq k \in\{H, F\}$. The outcome of this comparison depends on the size of migration gains $\mu^{j} W^{j}\left[\chi^{j} /(1+\theta)-1\right]$, which are part of $S W$ in (13), but are not considered in the $W^{c}$-maximizing contract. Hence, the social planner is more likely to opt for a migration equilibrium in order to reap the migration gains of mobile high-skilled labor.

The numerical results summarized in Tables 1 and 2 illustrate the differences between rational non-cooperative policies, bilateral coordination, and the social planner solution for the two different belief scenarios. Thereby, $A^{H} \geq A^{F}$ has been assumed. The numerical analysis accounts for interior solutions (with $G^{H}, G^{F}>0$ ) as well as corner solutions (with $G^{H}>0, G^{F}=0$ ). Table 1 refers to the baseline case of stay-home beliefs. Furthermore, relatively high migration costs are assumed $(\theta=0.09)$. In this case, non-cooperative policies of rational governments lead to an equilibrium without migration if the two countries are equally productive $\left(A^{H}=A^{F}\right) \cdot{ }^{25}$ By contrast, if productivity differences are sufficiently high, a Nash equilibrium in pure strategies does not exist. From Lemma 2 we know that $G_{0}^{j}=\left(\beta b A^{j} / \phi^{\beta}\right)^{1 /(1-\beta)}$ is the optimal decision of government $j$ in the case of non-migration. Hence, a higher productivity differential $A^{H} / A^{F}$ leads to a higher differential in education expenditure $G_{0}^{H} / G_{0}^{F}$. This, however, makes it more attractive for the less productive country $F$ to deviate from policy $G_{0}^{F}$ because the gains from a successful deviation in the form of inflowing efficiency units of high-skilled labor increase with the education expenditure in country $H$. The incentive of the technologically backward economy to lower its education expenditure strategically explains why a Nash equilibrium without migration does not exist if the productivity differential $A^{H} / A^{F}$ is sufficiently high. (A Nash equilibrium with brain drain does not exist either if migration behavior is based on stay-home beliefs. See the discussion in Subsection 6.2.)

According to part (i) of Proposition 2, there is no benefit from a bilateral contract if non-migration is realized in the non-cooperative game of rational governments. However, a bilateral contract may help to implement an equilibrium when non-cooperative policy

\footnotetext{
${ }^{25}$ The outcome $G^{j}=W^{j}$ in an equilibrium without migration is due to the particular parameter choice $\beta=1 / 2$. If $\beta \neq 1 / 2$, then $G^{j}$ and $W^{j}$ do no longer coincide.
} 


\begin{tabular}{|c|c|c|c|c|}
\hline$A^{H} / A^{F}$ & & Non-cooperative & Coordination & Social Planner \\
\hline 1 & $\begin{array}{l}G^{H}, G^{F} \\
G^{H}+G^{F} \\
W^{H}, W^{F} \\
W^{H}+W^{F} \\
S W \\
\text { migration }\end{array}$ & $\begin{array}{c}\text { 104.17, } 104.17 \\
\mathbf{2 0 8 . 3 3} \\
104.17,104.17 \\
\mathbf{2 0 8 . 3 3} \\
\mathbf{2 0 8 . 3 3} \\
\text { non-migration }\end{array}$ & $\begin{array}{c}104.17,104.17 \\
208.33 \\
\\
208.33 \\
208.33 \\
\text { non-migration }\end{array}$ & $\begin{array}{c}104.17,104.17 \\
\mathbf{2 0 8 . 3 3}\end{array}$ \\
\hline 3 & $\begin{array}{l}G^{H}, G^{F} \\
G^{H}+G^{F} \\
W^{H}, W^{F} \\
W^{H}+W^{F} \\
S W \\
\text { migration }\end{array}$ & no equ & $\begin{array}{c}937.50,104.17 \\
\text { 1'041.67 } \\
\\
\text { 1'041.67 } \\
\text { 1'041.67 } \\
\text { non-migration }\end{array}$ & $\begin{array}{c}937.50,104.17 \\
\mathbf{1 ' 0 4 1 . 6 7} \\
\\
\text { 1'041.67 } \\
\text { non-migration }\end{array}$ \\
\hline 8 & $\begin{array}{l}G^{H}, G^{F} \\
G^{H}+G^{F} \\
W^{H}, W^{F} \\
W^{H}+W^{F} \\
S W \\
\text { migration }\end{array}$ & no equilibrium & $\begin{array}{c}6^{\prime} 666.70,104.17 \\
\mathbf{6}^{\prime} \mathbf{7 7 0 . 8 7} \\
\mathbf{6}^{\prime} \mathbf{7 7 0 . 8 7} \\
\mathbf{6}^{\prime} \mathbf{7 7 0 . 8 7} \\
\text { non-migration }\end{array}$ & $\begin{array}{c}6^{\prime} 774.54,0 \\
6^{\prime} \mathbf{7} 74.54\end{array}$ \\
\hline
\end{tabular}

Table 1: Comparison of non-cooperative policies, bilateral coordination, and the social planner solution if migration behavior is based on stay-home beliefs. $\left(\beta=1 / 2, A^{F}=\right.$ $50, \bar{e}=1 / 3, q=0.0015$ and $\theta=0.09)$

setting leads to an ongoing struggle for mobile high-skilled labor. These insights are confirmed by the second column in Table 1. According to the third column, the outcome of coordination may also be optimal from a social planner's point of view (see rows 1 and 2). This is, however, not always the case. If the productivity differential $A^{H} / A^{F}$ is sufficiently high (row 3), it may be beneficial from a social planner's point of view to realize the migration gains of mobile high-skilled workers by setting education policies in a way that triggers brain drain from $H$ to $F$. This confirms our previous finding that bilateral coordination is biased toward non-migration. To get an intuition of the direction of the brain drain (from the high-productivity to the low-productivity economy), note that a bilateral contract leads to a more generous level of education expenditure in the technologically advanced economy, that is, $G_{0}^{H}>G_{0}^{F}$ since $A^{H}>A^{F}$. By raising $G^{H}$ above $G_{0}^{H}$ and reducing $G^{F}$ to below $G_{0}^{F}$, the social planner triggers brain drain from $H$ to $F$ and increases the utility of high-skilled migrants. The technologically backward 
economy $F$ gains due to the inflow of well-educated, high-skilled workers from country $H$. Because of the large productivity differential and the (relatively) low migration cost, it is not surprising that the social planner educates people only in the technologically advanced country, letting migrants provide high-skilled labor in the low-productivity country. ${ }^{26}$

\begin{tabular}{|c|c|c|c|c|}
\hline$A^{H} / A^{F}$ & & Non-cooperative & Coordination & Social Planner \\
\hline \multirow[t]{6}{*}{9} & $G^{H}, G^{F}$ & \multirow{6}{*}{ no equilibrium } & $8^{\prime} 426.73,114.20$ & $8^{\prime} 560.32,0$ \\
\hline & $G^{H}+G^{F}$ & & 8'540.93 & 8'560.32 \\
\hline & $W^{H}, W^{F}$ & & & \\
\hline & $W^{H}+W^{F}$ & & $8^{\prime} 541.48$ & \\
\hline & $S W$ & & 8'541.49 & 8'560.32 \\
\hline & migration & & $F \rightarrow H$ & $H \rightarrow F$ \\
\hline \multirow[t]{6}{*}{11} & $G^{H}, G^{F}$ & $12^{\prime} 566.45,108.86$ & $12^{\prime} 604.09,118.98$ & $12^{\prime} 747.28,0$ \\
\hline & $G^{H}+G^{F}$ & $12 ' 675.30$ & $12 ' 723.07$ & $12 ' 747.28$ \\
\hline & $W^{H}, W^{F}$ & $12^{\prime} 585.32,120.18$ & & \\
\hline & $W^{H}+W^{F}$ & $12^{\prime} 705.51$ & $12^{\prime} 707.90$ & \\
\hline & $S W$ & $12^{\prime} 707.23$ & $12^{\prime} 707.93$ & $12^{\prime} 747.28$ \\
\hline & migration & $H \rightarrow F$ & $F \rightarrow H$ & $H \rightarrow F$ \\
\hline \multirow[t]{6}{*}{13} & $G^{H}, G^{F}$ & $17^{\prime} 551.48,0$ & $17^{\prime} 604.11,124.02$ & $17^{\prime} 765.07,0$ \\
\hline & $G^{H}+G^{F}$ & $17^{\prime} 551.48$ & $17^{\prime} 728.13$ & $17^{\prime} 765.07$ \\
\hline & $W^{H}, W^{F}$ & $17^{\prime} 577.85,128.28$ & & \\
\hline & $W^{H}+W^{F}$ & $17^{\prime} 706.12$ & $17^{\prime} 707.56$ & \\
\hline & $S W$ & $17^{\prime} 764.43$ & $17^{\prime} 707.59$ & $17^{\prime} 765.07$ \\
\hline & migration & $H \rightarrow F$ & $F \rightarrow H$ & $H \rightarrow F$ \\
\hline
\end{tabular}

Table 2: Comparison of non-cooperative policies, bilateral coordination, and the social planner solution if migration behavior is based on go-abroad beliefs. $\left(\beta=1 / 2, A^{F}=\right.$ $50, \bar{e}=1 / 3, q=0.0015$ and $\theta=0.01)$

In the numerical examples shown in Table 2 , we consider low migration costs $(\theta=$ 0.01) and assume that mobile high-skilled workers base their migration decisions on goabroad beliefs. Then the non-cooperative policy game of rational governments does not settle at an equilibrium if the productivity differential $A^{H} / A^{F}$ is too low. If, on the contrary, $A^{H} / A^{F}$ is sufficiently high, migration from the high-productivity country to the

\footnotetext{
${ }^{26}$ Two remarks are in order here. First, the values of $S W$ and $G^{H}+G^{F}$ are not identical. But the respective difference is rather small, due to the particular parameter choice with $\beta=1 / 2$ and a low value of $q$. Second, a social planner solution with brain drain from $H$ to $F$ does not necessarily require $G^{F}=0$. For example, if $A^{H} / A^{F}=7.64$, the social planner would choose positive levels of education expenditures in both countries, despite migration of high-skilled workers from high-productivity country $H$ to low-productivity country $F$.
} 
less developed economy is the outcome of the non-cooperative policy game. By offering a good education system, the advanced country endows its high-skilled labor force with a high level of efficiency units. It does not care about policy in the technologically backward economy if the productivity differential is sufficiently pronounced. ${ }^{27}$ The median voter of the country with low total factor productivity can benefit from attracting well-educated high-skilled workers from abroad rather than educating such workers at home. This explains the outcome of the non-cooperative policy game reported in the first column of Table 2.

The second column of Table 2 shows again that bilateral coordination of education policies helps to avoid an ongoing battle for mobile educated workers. Moreover, bilateral coordination may change the pattern of brain drain and lead to higher levels of public education expenditure than a non-cooperative equilibrium with migration. However, we know from the theoretical analysis that the migration pattern under bilateral coordination is not necessarily efficient. This is confirmed by the third column. In all cases, the social planner prefers migration from country $H$ to country $F$ and thereby chooses a different migration pattern than the one resulting from policy coordination. This migration pattern may coincide, however, with the one implied by non-cooperative policy setting. By also accounting for the utility of high-skilled migrants, the social planner decides in favor of higher total public education expenditure. The last set of results in Table 2 ("Non-cooperative" and "Coordination" $S W$ for $A^{H} / A^{F}=13$ ) indicates that from the social planner's point of view, the change in the pattern of brain drain through bilateral coordination can even lead to a loss in welfare compared to the non-cooperative equilibrium.

The main insights regarding the social planner solution can be summarized as follows:

Proposition 3 Bilateral coordination can help to increase public education expenditure to above suboptimal non-cooperative levels. Moreover, it is useful for overcoming an ongoing

\footnotetext{
${ }^{27}$ The result that a country with higher economic capacity cares less about policy setting in other economies is well in line with insights from textbook models of tax competition. However, in contrast to these textbook models, asymmetries in total factor productivities (and not asymmetries in population size) are responsible for the different economic capacities of countries $H$ and $F$ in our framework.
} 
battle for mobile high-skilled workers. However, (i) bilateral coordination is biased toward non-migration, and (ii) it may reverse the direction of brain drain compared to both the non-cooperative policy game and the social planner solution; (iii) from a social planner's point of view, non-cooperative education policies can be better than bilateral coordination.

Proof. Analysis in the text.

\section{Concluding Remarks}

This paper analyzed opportunities of and incentives for national governments to provide higher education and to compete for educated workers in a simple two-country model in which brain drain has agglomeration effects because it affects the tax base in the source and the receiver country. We examined the scope for a national education policy that is consistent with an avoidance of brain drain as well as the possibilities for changing a given migration pattern. And we compared education levels, migration patterns, and welfare in non-cooperative political equilibria with the outcomes under bilateral coordination and the social planner solution.

Our results suggest that non-cooperative education policies can have severe consequences. If governments are fully rational and take into account the fact that they can influence the pattern of high-skilled labor migration, fiscal competition provides an incentive for lowering public education expenditure in order to prevent an outflow or to induce an inflow of high-skilled workers. The incentive to attract mobile high-skilled workers may lead to an ongoing struggle between non-cooperative governments and failure to settle at an equilibrium.

However, our analysis also suggests that, contrary to the recommendations of policymakers, one should not be too optimistic about achieving an optimal solution from policy coordination between national governments. On the one hand, bilateral coordination may have the merits of raising public education expenditure above the suboptimal noncooperative levels and of preventing an ongoing battle for mobile high-skilled labor. On the

other hand, it is biased against migration because governments serving the median voter 
neglect the gains of high-skilled migrants. As a consequence, from a utilitarian planner's point of view, bilateral coordination may be even worse than a non-cooperative equilibrium. This highlights the desirability of reshaping national education policies toward an integrated perspective that takes the interests of high-skilled migrants into account.

There are several limitations to our analysis that would be worth addressing in future research. For instance, we have imposed rather restrictive assumptions on education technology and individual education costs (non-rivalry, constant returns to scale, identical learning abilities). These assumptions allowed us to isolate the consequences of strategically lowering public education expenditure from other causes of brain drain. In this framework, non-cooperative policy setting by rational governments may lead to either non-migration or to brain drain from a high-productivity to a low-productivity economy. ${ }^{28}$

A further limitation of our analysis is the fact that by focusing on fiscal externalities we have ignored intertemporal externalities from migration of high-skilled labor - such as changes in productivity. Allowing for external productivity gains in the host country and/or losses in the source country would not qualitatively affect the equilibrium analysis for given education policies because it leads to further agglomeration effects that go in the same direction as those triggered by the tax base effect of migration. However, such an extension may alter the results for fiscal competition and policy coordination. Another interesting extension toward more realism would be to consider a multi-industry model in which promotion of attractive workplaces for high-skilled workers (e.g., through research policy) complements education policy.

\section{References}

Andersson, Fredrik and Kai A. Konrad (2003), Human capital investment and globalization in extortionary states, Journal of Public Economics 87, 1539-1555.

\footnotetext{
${ }^{28}$ In an extension to our basic framework, we have accounted for diseconomies of scale in the education production technology. Simulation results for this modified model show that brain drain from the lowproductivity to the high-productivity country is a possible outcome of the non-cooperative policy game between rational governments (if the diseconomies of scale are sufficiently strong).
} 
Becker, Sasha O., Andrea Ichino and Giovanni Peri (2004), How large is the "brain drain" from Italy?, Giornale degli Economisti e Annali di Economia 63, 1-32.

Beine, Michel, Frédéric Docquier and Hillel Rapoport (2001), Brain drain and economic growth: theory and evidence, Journal of Development Economics 64, 275-289.

Bhagwati, Jagdish N. and William Dellalfar (1973), The Brain drain and income taxation, World Development 1, 94-101.

Bhagwati, Jagdish N. and Koichi Hamada (1974), The brain drain, international integration of markets for professionals and unemployment, Journal of Development Economics 1, 19-42.

Bhagwati, Jagdish N. and John D. Wilson, eds. (1989), Income Taxation and International Mobility, Cambridge, MA: MIT Press.

Bound, John and Sarah Turner (2006), International flows of skilled workers: Estimates of the effects of skilled workers, unpublished mansucript, University of Virginia.

Bucovetsky, Sam (2003), Efficient migration and redistribution, Journal of Public Economics 87, 2459-2474.

Council of Europe (1995), Recommendation No. R (95) 7 of the Committee of Ministers to member states on brain drain in the sectors of higher education and research.

Haupt, Alexander and Eckhard Janeba (2004), Education, redistribution, and the threat of brain drain, NBER Working Paper No. 10618.

Justman, Moshe and Jacques-Francois Thisse (1997), Implications of the mobility of skilled labor for local public funding of higher education. Economics Letters 55, 409-412.

Justman, Moshe and Jacques-Francois Thisse (2000), Local public funding of higher education when skilled labor is mobile. International Tax and Public Finance 7, $247-258$. 
Lucas, Robert E.B. (2005), International migration and economic development: Lessons from low-income countries, Edward Elgar.

OECD (2006a), International migration outlook, OECD, Paris.

OECD (2006b), Education at a glance, OECD, Paris.

Poutvaara, Panu (2004a), Educating Europe: Should public education be financed with graduate taxes or income-contingent loans?, CESifo Economic Studies 50, 663-684.

Poutvaara, Panu (2004b), Public education in an integrated Europe: Studying to migrate and teaching to stay?, CESifo Working Paper No. 1369.

Poutvaara, Panu and Vesa Kanniainen (2000), Why invest in your neighbor? Social contract on educational investment, International Tax and Public Finance 7, 547-562.

Schmitt, Nicolas and Antoine Soubeyran (2006), A simple model of brain circulation, Journal of International Economics 69, 269-309

Stark, Oded, Christian Helmenstein and Alexia Prskawetz (1997), A brain gain with a brain drain, Economics Letters 55, 227-234.

Uebelmesser, Silke (2006), To go or not to go: Emigration from Germany, German Economic Review 7, 211-231.

Wildasin, David E. (2000), Labor-market integration, investment in risky human capital, and fiscal competition, American Economic Review 90, 73-95.

\section{Appendix A. Proofs}

\section{Proof of Lemma 1}

According to (1), the demand for the two factors $S^{j}$ and $L^{j}$ at location $j=H, F$ is given by

$$
w_{S}^{j}=A^{j} \beta\left(L^{j} / S^{j}\right)^{1-\beta}, \quad w_{L}^{j}=A^{j}(1-\beta)\left(L^{j} / S^{j}\right)^{-\beta},
$$


which implies that

$$
\omega^{j}=\frac{\beta}{1-\beta} \frac{L^{j}}{S^{j}}
$$

Combining (4) and (15), we obtain

$$
\frac{S^{j}}{L^{j}}=\frac{\beta G^{j}}{\phi(1-\beta)}
$$

for the skill intensity in equilibrium.

In order to characterize equilibrium employment, we first consider a scenario without migration. With $\mu^{j}=\mu^{k}=0$, we have $S^{j}=(1-\bar{e})\left(1-L^{j}\right) G^{j}$ and thus, according to (16), in equilibrium,

$$
L_{0}^{j}=1-\beta, \quad S_{0}^{j}=\beta G^{j} / \phi
$$

(Non-migration equilibrium values are indicated by subscript 0 .) If migration is allowed for, the equilibrium levels of employment are:

$$
L^{j}=L_{0}^{j}\left[1-\mu^{j}+\mu^{k} G^{k} / G^{j}\right], \quad S^{j}=S_{0}^{j}\left[1-\mu^{j}+\mu^{k} G^{k} / G^{j}\right]
$$

Substitute (2) for $S^{j}$ into (16) and solve for $L^{j}$. Then substitute $L^{j}$ into (16) and solve for $S^{j}$.

Substituting (16) into (14), we further obtain

$$
w_{S}^{j}=b A^{j}\left(\phi / G^{j}\right)^{1-\beta}
$$

with $b \equiv \beta^{\beta}[(1-\beta)]^{1-\beta}$. Education expenditure is financed by a wage income tax with tax rate $\tau^{j}$. The budget constraint in country $j$ is thus:

$$
G^{j}=\tau^{j} Y^{j}=\tau^{j}\left[w_{S}^{j} S^{j}+w_{L}^{j} L^{j}\right]
$$

The tax burden per efficiency unit of high-skilled labor $\tau^{j} w_{S}^{j}$ is equal to the ratio $w_{S}^{j} G^{j} / Y^{j}$. This implies for the closed economy that $\tau^{j} w_{S}^{j}=w_{S}^{j} G^{j} / Y_{0}^{j}=\phi$. (Use $L_{0}^{j}=1-\beta$, 
according to (17), and note that $1-\beta$ is the income share of low-skilled labor: $1-\beta=$ $w_{L}^{j} L_{0}^{j} / Y_{0}^{j}$. Then $Y_{0}^{j}=w_{L}^{j}$ and $w_{S}^{j} G^{j} / Y_{0}^{j}=\phi$ follows from (4).) Using (18) in (1), we have $Y^{j}=Y_{0}^{j}\left[1-\mu^{j}+\mu^{k} G^{k} / G^{j}\right]$. Hence, under migration,

$$
\tau^{j} w_{S}^{j}=\frac{\phi}{1-\mu^{j}+\mu^{k} G^{k} / G^{j}} .
$$

A positive net wage requires $w_{S}^{j}>\tau_{S}^{j} w_{S}^{j}$. A sufficient condition is $w_{S}^{j}>\phi /\left(1-\mu^{j}\right)$, which, after substitution of (19) implies (6). Equ. (7) follows from combining (19) and (21). QED.

\section{Proof of Lemma 2}

Equ. (11) follows from (4), (19) and (21). Partial differentiation of (11) with respect to $G^{j}$ gives

$$
\frac{\partial W^{j}}{\partial G^{j}}=\frac{1}{G^{j}}\left[\beta b A^{j}\left(G^{j} / \phi\right)^{\beta}-\frac{G^{j}}{\left[1-\mu^{j}+\mu^{k} G^{k} / G^{j}\right]}-\frac{\mu^{k} G^{k}}{\left[1-\mu^{j}+\mu^{k} G^{k} / G^{j}\right]^{2}}\right],
$$

and $\partial W^{j} / \partial G^{j}=0$ implicitly determines a unique $G^{j}=\tilde{G}^{j}\left(\mu^{j}, \mu^{k} ; G^{k}\right)$. Moreover, $\partial^{2} W^{j} /\left.\left(\partial G^{j}\right)^{2}\right|_{G^{j}=\tilde{G}^{j}(\cdot)}<0$. Thus, $G^{j}=\tilde{G}^{j}\left(\mu^{j}, \mu^{k} ; G^{k}\right)$ is the best response of $j$ to $G^{k}$ for given $\mu^{j}, \mu^{k}$.

Applying the implicit function theorem to $\partial W^{j} / \partial G^{j}=0$, we have

$$
\frac{\partial \tilde{G}^{j}(\cdot)}{\partial x}=-\frac{\partial^{2} W^{j} /\left.\partial G^{j} \partial x\right|_{G^{j}=\tilde{G}^{j}(\cdot)}}{\partial^{2} W^{j} /\left.\left(\partial G^{j}\right)^{2}\right|_{G^{j}=\tilde{G}^{j}(\cdot)}}
$$

for any $x \in\left\{\mu^{j}, \mu^{k}, G^{k}\right\}$. With $\partial^{2} W^{j} /\left.\partial G^{j} \partial \mu^{j}\right|_{G^{j}=\tilde{G}^{j}(\cdot)}<0, \partial^{2} W^{j} /\left.\partial G^{j} \partial \mu^{k}\right|_{G^{j}=\tilde{G}^{j}(\cdot)}>0$, and $\partial^{2} W^{j} /\left.\partial G^{j} \partial G^{k}\right|_{G^{j}=\tilde{G}^{k}(\cdot)}>0$ if $\mu^{k} \in(0, q]$, the partial derivatives of $\tilde{G}^{j}(\cdot)$ follow. Part (iv) of the lemma follows from (22) and $\partial W^{j} /\left.\partial G^{j}\right|_{G^{j}=\tilde{G}^{j}(\cdot)}=0$. QED. 


\section{Proof of Proposition 2}

Without loss of generality, let us focus on $\mu^{H} \geq 0, \mu^{F}=0$ in this proof. (The arguments for $\mu^{H}=0, \mu^{F} \geq 0$ can be derived in an analogous way.) Moreover, let us restrict our analysis to a parameter domain that guarantees $G^{H}, G^{F}>0$ in a Nash equilibrium with migration (under rational policy setting) as well as under bilateral policy coordination.

Denote by $\left.\Delta W^{j} \equiv W^{j}\right|_{\mu^{H}=q}-\left.W^{j}\right|_{\mu^{H}=0}$ the migration gains/losses of the median voter in country $j=H, F$ if at given $G^{H}, G^{F}$ an equilibrium with migration instead of one without migration is realized. Moreover, let $\Delta W^{c} \equiv \Delta W^{H}+\Delta W^{F}$. According to (11), we obtain

$$
\begin{aligned}
\Delta W^{H} & =-\frac{q G^{H}}{(1-q)}, \\
\Delta W^{F} & =\frac{q G^{H}}{\left(1+q G^{H} / G^{F}\right)} .
\end{aligned}
$$

As a consequence, $\Delta W^{c}<0$ for any positive $G^{H}$, so that governments prefer $\mu^{H}=\mu^{F}=0$ to $\mu^{H}=q$ and $\mu^{F}=0$ under coordination. Hence, for a given $\left(G^{H}, G^{F}\right), W^{c}$ is highest if $\mu^{H}=\mu^{F}=0$. Furthermore, partially differentiating (12) with respect to $G^{j}$ gives

$$
\frac{\partial W^{c}}{\partial G^{j}}=\frac{\partial W^{H}}{\partial G^{j}}+\frac{\partial W^{F}}{\partial G^{j}}
$$

For $\mu^{H}=\mu^{F}=0,(26)$ implies $\partial W^{c} / \partial G^{j}=\partial W^{j} / \partial G^{j}$, according to (11). Together with $\Delta W^{c}<0$, this proves part (i) of Proposition 2.

Concerning part (ii) of the proposition, we know from the analysis in Sections 5 and 6 that for sufficiently small migration costs $\theta$, education policies $G_{0}^{H}, G_{0}^{F}$ are inconsistent with non-migration if migration decisions are based on go-abroad beliefs. Furthermore, the numerical results in Table 2 show that in this case median voters may benefit from coordination of policies that allow for migration of high-skilled workers.

Finally, according to our analysis in Section $6, G^{H}=\tilde{G}^{H}\left(q, 0, G^{F}\right), G^{F}=$ $\tilde{G}^{F}\left(0, q, G^{H}\right)$ in a non-cooperative policy equilibrium with $\mu^{H}=q, \mu^{F}=0$. In view 
of (11) and (26), we have

$$
\begin{aligned}
\frac{\partial W^{c}}{\partial G^{H}} & =\frac{\partial W^{H}}{\partial G^{H}}+\frac{\partial W^{F}}{\partial G^{H}} \\
\frac{\partial W^{c}}{\partial G^{F}} & =\frac{\partial W^{F}}{\partial G^{F}} .
\end{aligned}
$$

By definition, $\partial W^{H} / \partial G^{H}=\partial W^{F} / \partial G^{F}=0$ at $G^{H}=\tilde{G}^{H}\left(q, 0, G^{F}\right), G^{F}=\tilde{G}^{F}\left(0, q, G^{H}\right)$. Moreover, differentiating (22) and evaluating the resulting expression at $\mu^{H}=q, \mu^{F}=0$ gives

$$
\frac{\partial W^{F}}{\partial G^{H}}=\frac{q}{\left[1+q G^{H} / G^{F}\right]^{2}}>0 .
$$

As a consequence, $\partial W^{c}(\cdot) / \partial G^{H}>0$ at education policies $G^{H}=\tilde{G}^{H}\left(q, 0, G^{F}\right), G^{F}=$ $\tilde{G}^{F}\left(0, q, G^{H}\right)$, which implies that coordination gains exist. The numerical results in Table 2 show that the direction of brain drain may be reversed. This completes the proof of part (iii). QED.

\section{Appendix B. Derivation of (10) and Properties of $\rho_{1}^{H}$}

Substitute $(7)$ for $\chi^{H}(q)$ into $\chi^{H}(q)=1+\theta$ and rewrite the equation in the form

$$
\left(G^{H} / G^{F}\right)^{1-\beta}\left\{1+\eta \phi^{\beta}\left(G^{F}\right)^{1-\beta} /\left(b A^{F}\right)\right\}=(1+\theta) A^{H} / A^{F},
$$

where $\eta \equiv \frac{1+\theta}{1-q}-\frac{1}{1+q G^{H} / G^{F}}=\left(\theta+q \frac{1+G^{H} / G^{F}}{1+q G^{H} / G^{F}}\right) \frac{1}{1-q}>\theta$. Condition (30) defines $G^{H} / G^{F}$ as a decreasing function of $G^{F}$, starting at $G^{H} / G^{F}=\left[(1+\theta) A^{H} / A^{F}\right]^{1 /(1-\beta)}$ for $G^{F}=0$. With

$$
\rho_{1}^{H} \equiv\left\{(1+\theta) /\left[1+\eta \phi^{\beta}\left(G^{F}\right)^{1-\beta} /\left(b A^{F}\right)\right]\right\}^{1 /(1-\beta)}
$$

(30) can be written as $G^{H} / G^{F}=\rho_{1}^{H}\left(A^{H} / A^{F}\right)^{1 /(1-\beta)}$. Since $\eta>\theta, \rho_{1}^{H}<\rho_{0}^{H}$.

For the effect of a change in $\theta$, set $B \equiv \phi^{\beta}\left(G^{F}\right)^{1-\beta} /\left(b A^{F}\right)$ and note that $\partial \rho_{1}^{H} / \partial \theta>0$ 
if $1+\eta B>(1+\theta) \frac{B}{1-q}$. The latter condition is equivalent to $1>\frac{B}{1+q G^{H} / G^{F}}$ which, according to (19) and (21), is further equivalent to the condition $(1-\tau) w_{S}^{F}>0$. QED.

\section{Appendix C: Rational Governments and Brain Drain Reversal}

Individuals staying in $H$ rather than moving to $F$ save the cost of working abroad, while migrants from $F$ to $H$ have to incur this cost. Hence, any policy that induces workers educated in $F$ to work in $H$ implies avoidance of migration from $H$ to $F$ as well. Furthermore, if $H$ succeeds in preventing migration to $F$, country $F$ loses the agglomeration advantage coming from the tax base effect of brain drain. Thus, preventing the brain drain from $H$ to $F$ may be sufficient for inducing drain from $F$ to $H$. Figure 7 shows for two values of migration $\operatorname{costs}\left(\theta_{1}^{\prime}<\theta_{1}\right)$ the incentive constraint $I_{0}^{F}$ as well as deviation bound $D_{2}^{H}$ (which decreases with $G^{F}$ ). (Note that $I_{0}^{F}$ is the relevant incentive constraint for inducing reversed brain drain. See our assumptions regarding the beliefs that govern the migration decisions of mobile high-skilled workers in Section 5.) Under $\theta_{1}$, deviation cone $D C_{2}^{\prime}$ lies to the right of $G_{1}^{F}$ and is not feasible for $H$. However, if migration costs are sufficiently low $\left(\theta_{1}^{\prime}\right), H$ can induce reversed brain drain by reducing $G^{H}$ to reach $D C_{2}$. In particular, as $\theta$ approaches zero, $I_{0}^{F}$ coincides with the $E A$ line. Hence, $N_{1}$ (which is southeast of $N_{0}$ ) lies within the relevant deviation cone.

$>$ Figure $7<$ 


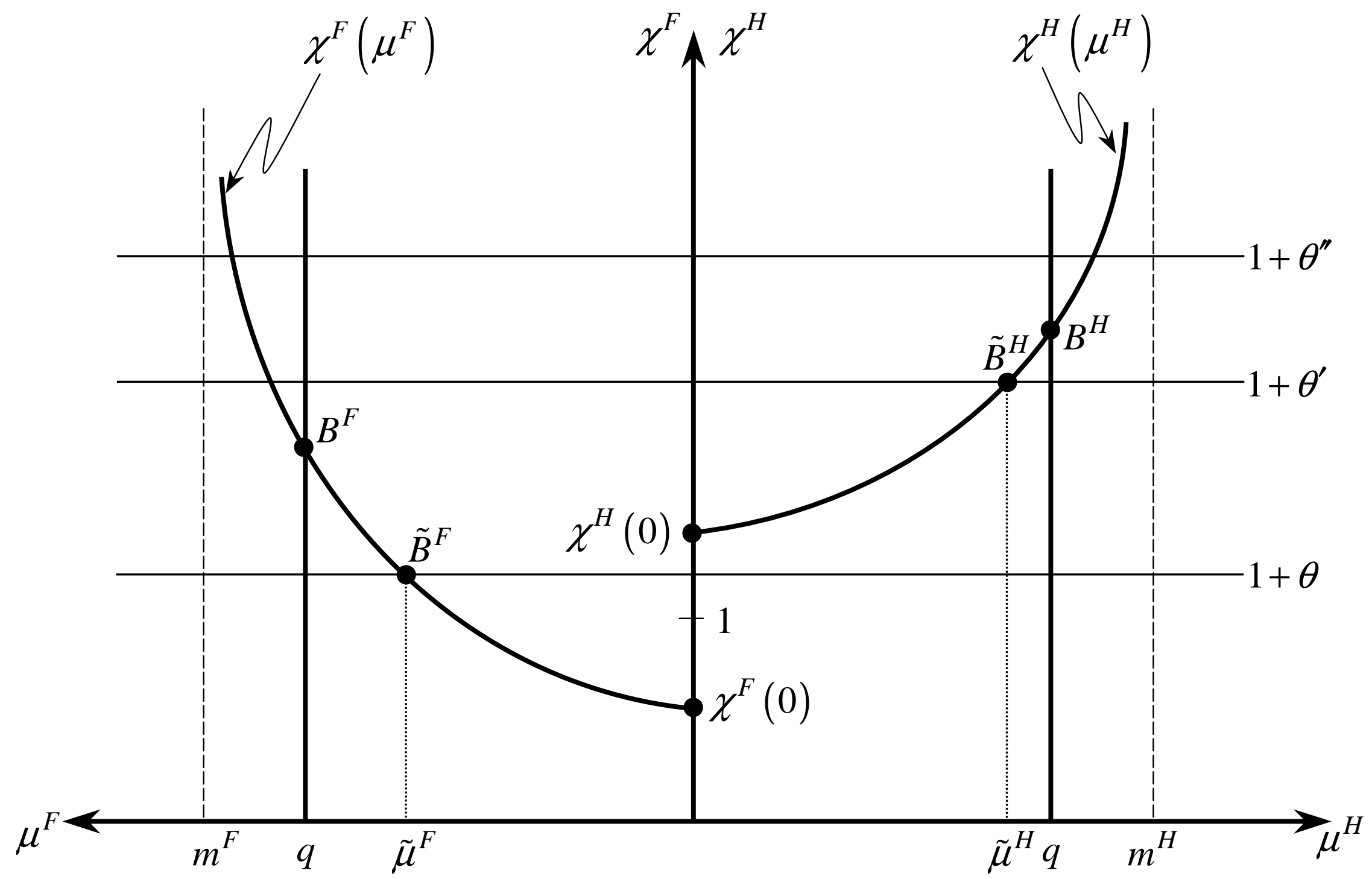

Figure 1. Migration incentives and migration equilibria: $G^{H} / G^{F} \geq\left(A^{H} / A^{F}\right)^{1 /(1-\beta)}$ 


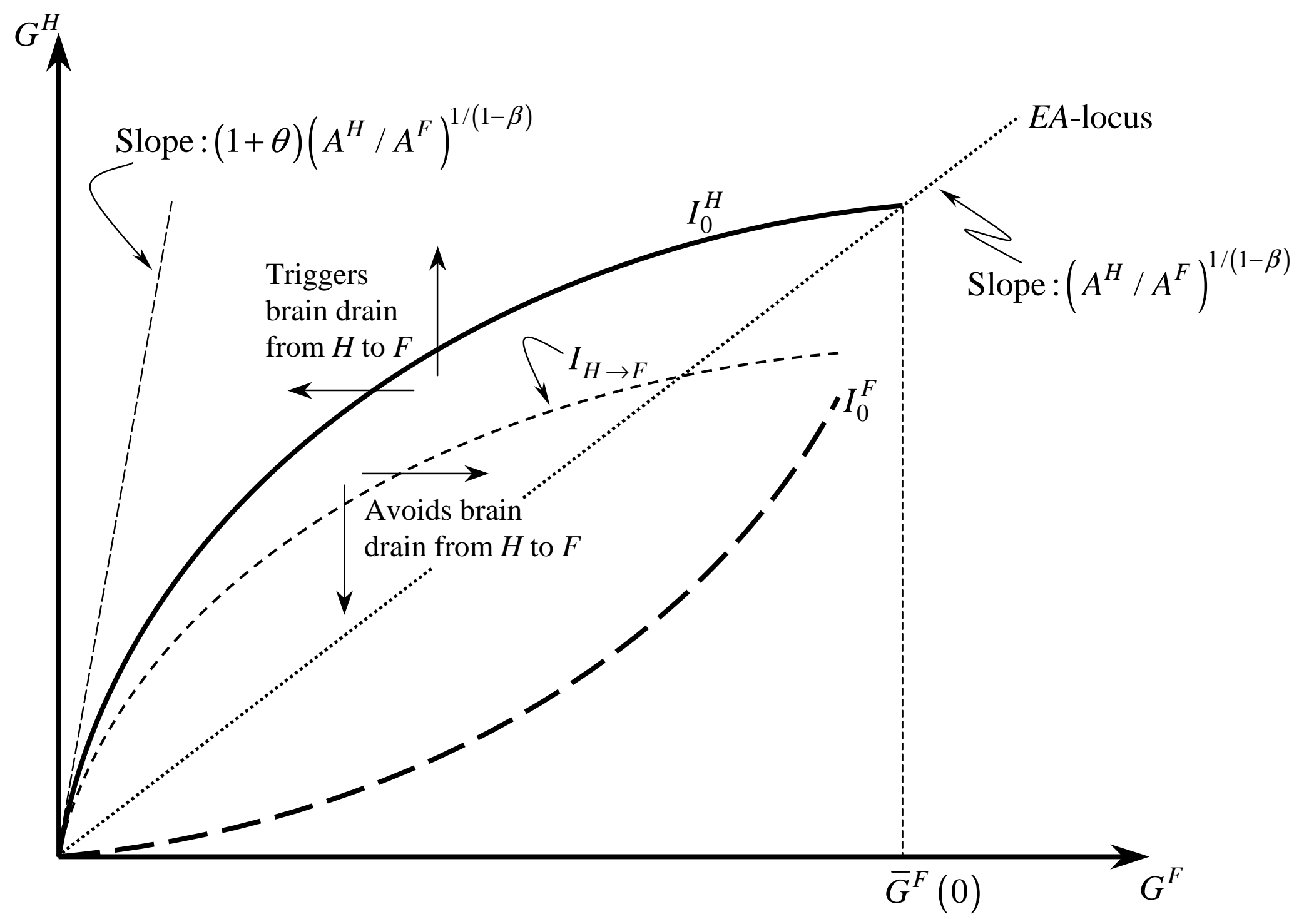

Figure 2. Scope for policy 


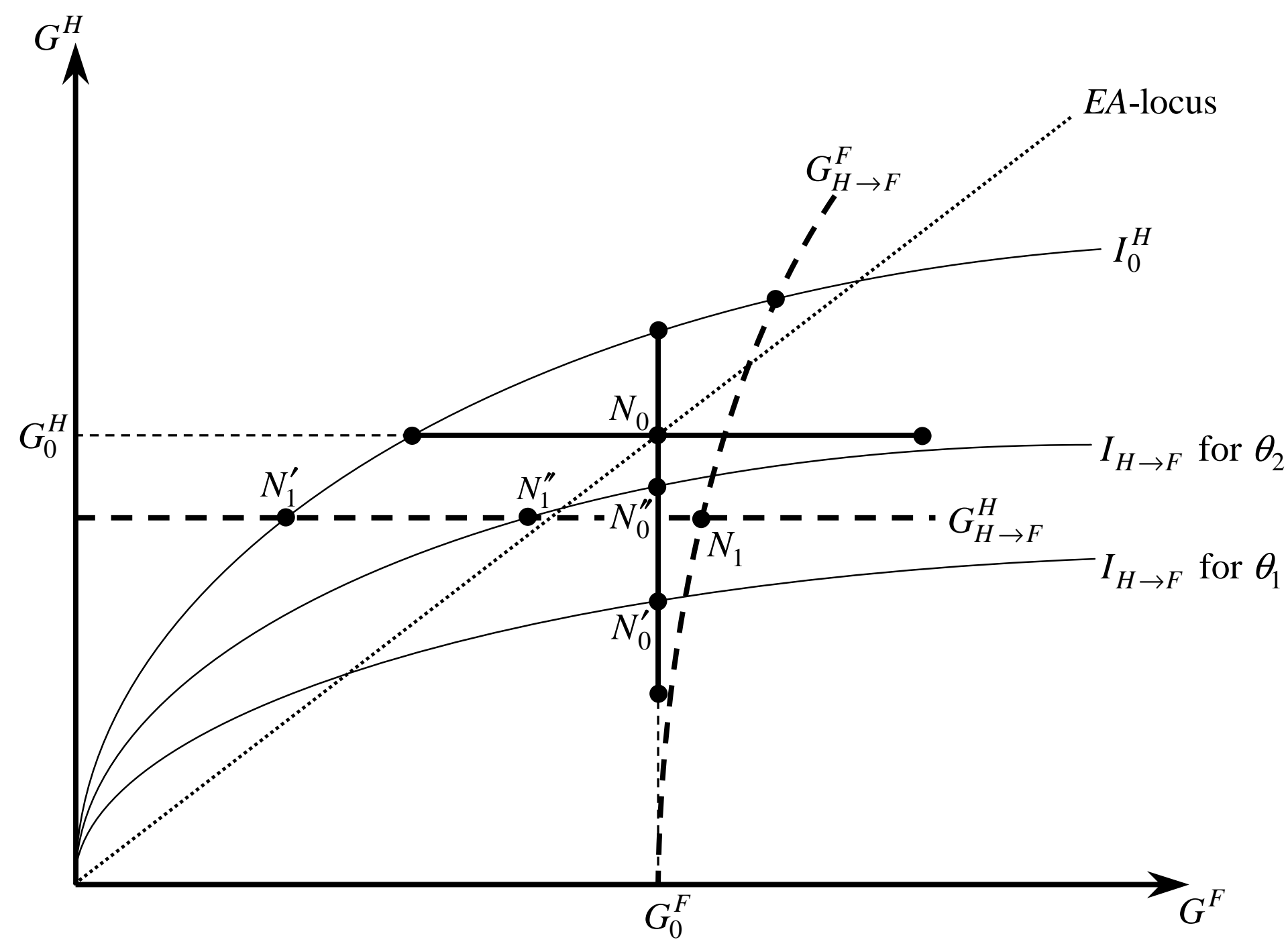

Figure 3. Non-sophisticated best replies $\left(\theta_{1}<\theta_{2}\right)$ 


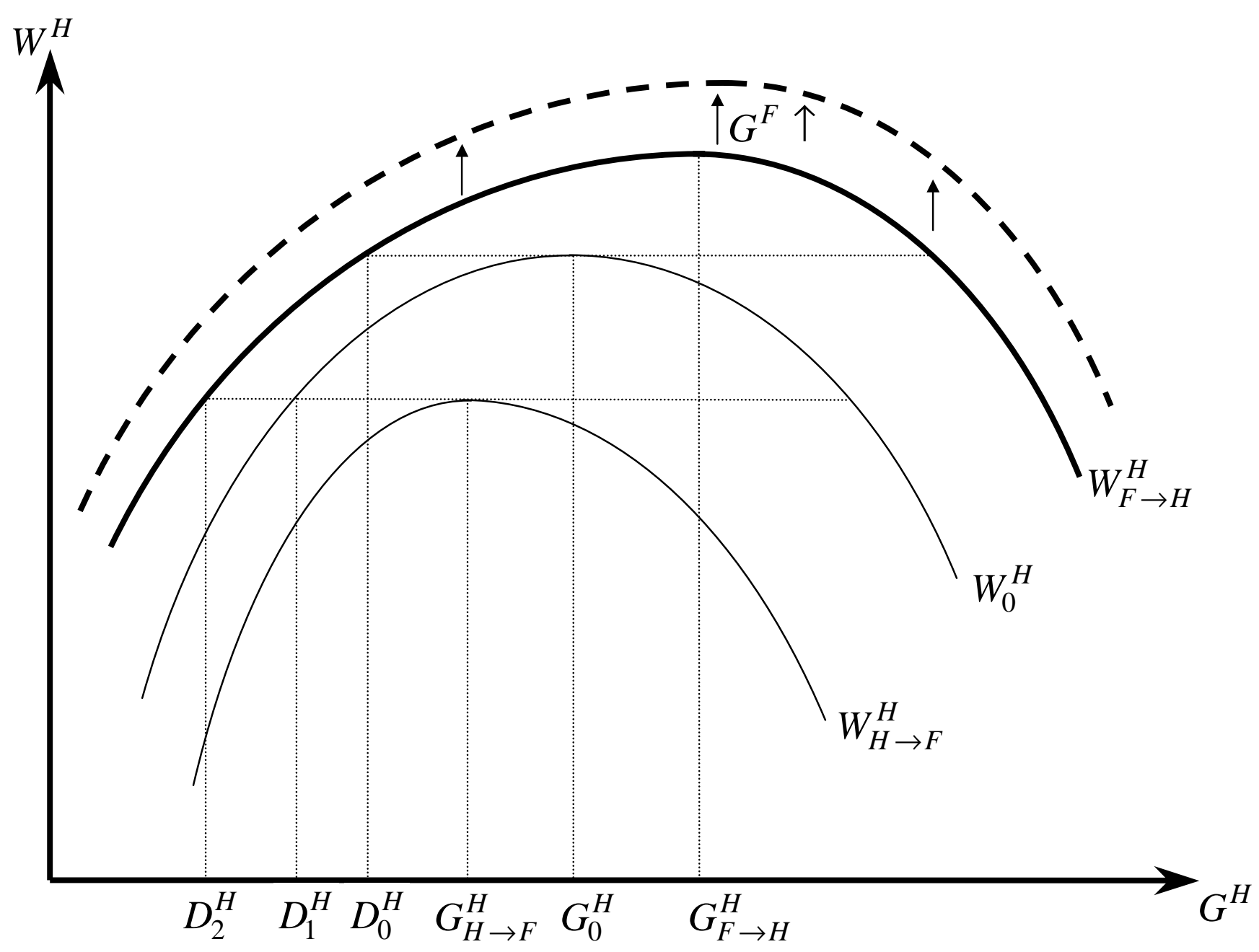

Figure 4. Optimal education policies for different migration patterns and deviation incentives 


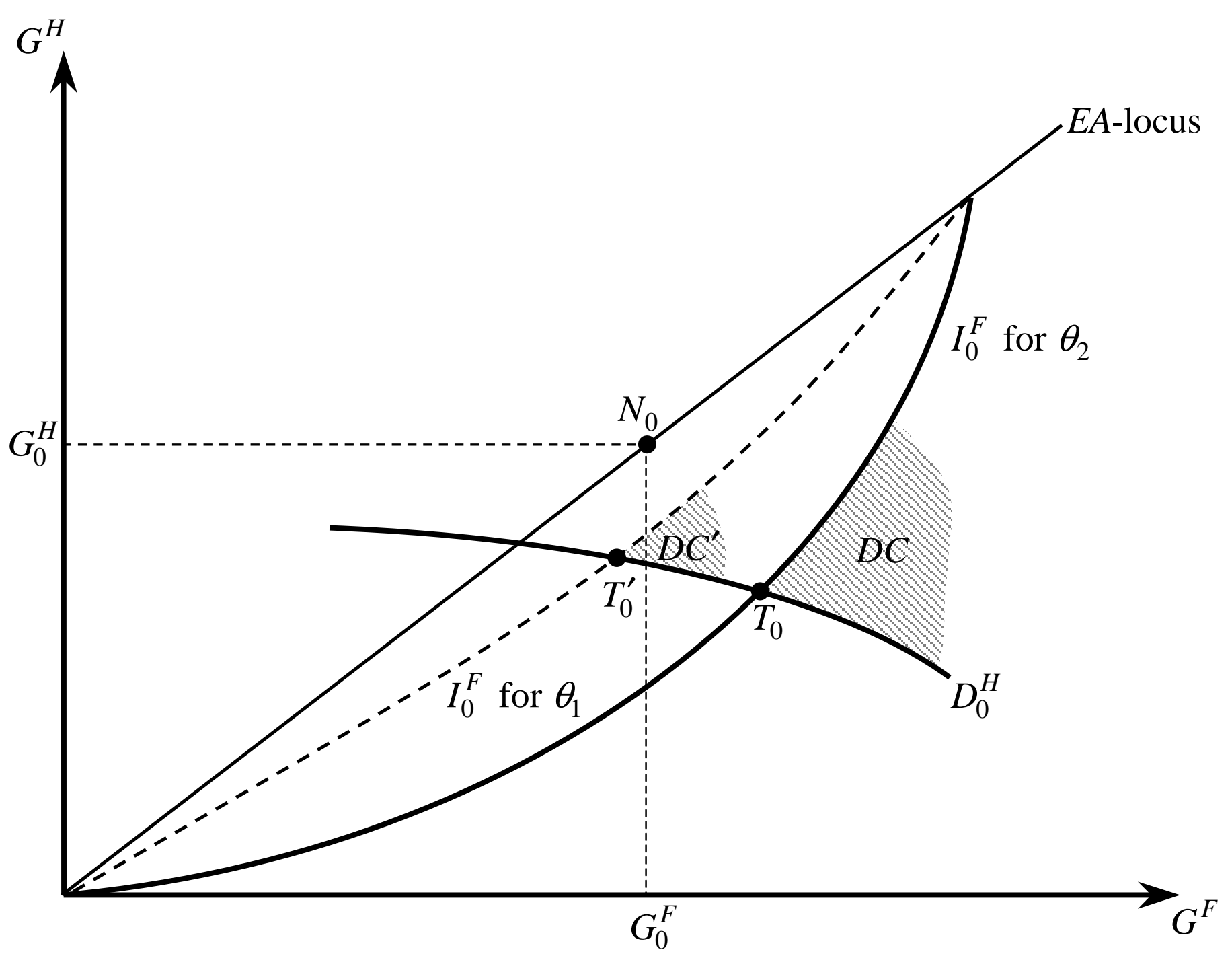

Figure 5. Deviation cones $(D C)$ from conditional non-migration equilibrium $\left(\theta_{1}<\theta_{2}\right)$ 


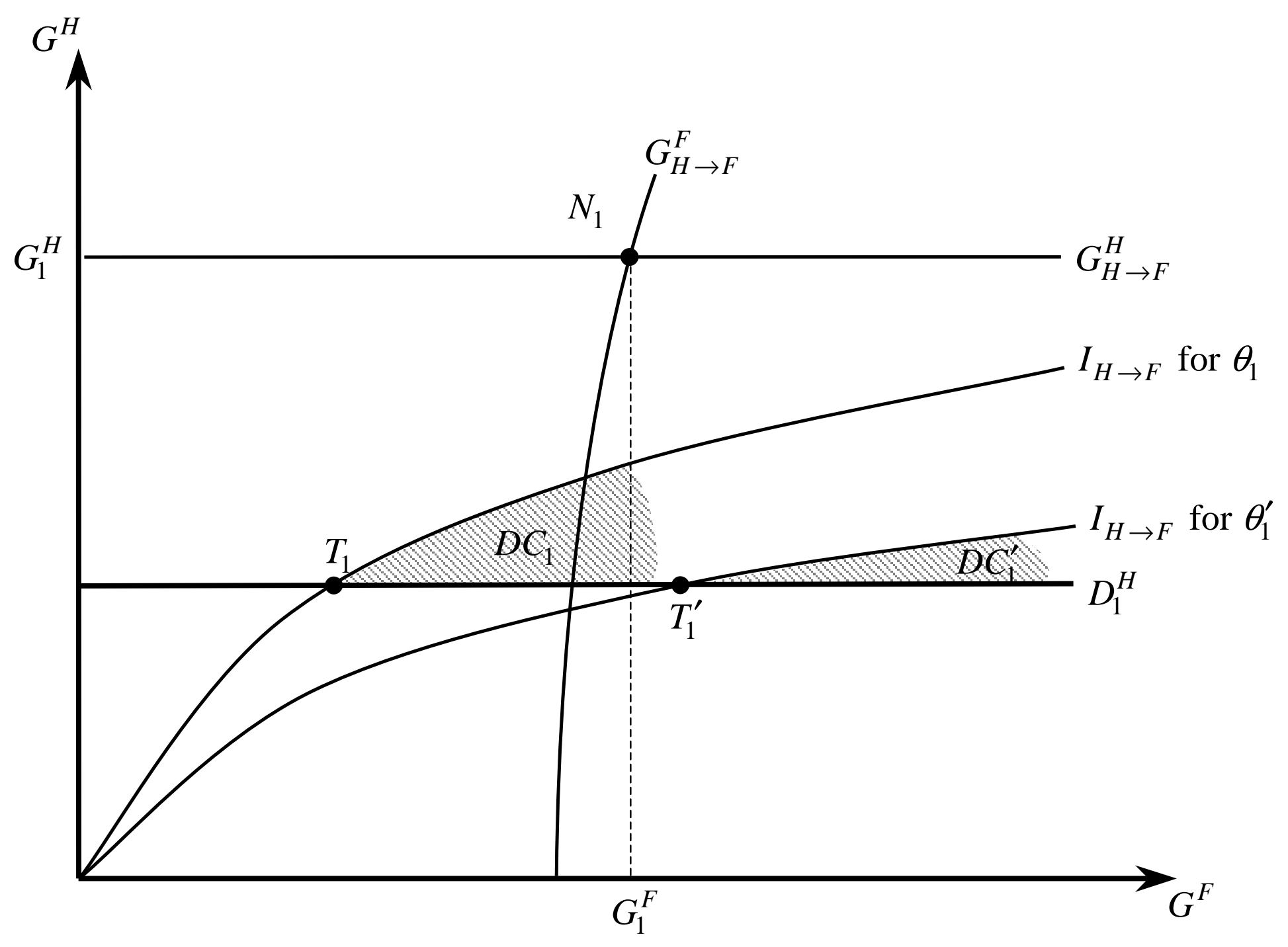

Figure 6. Deviation cones for return migration $\left(\theta_{1}^{\prime}<\theta_{1}\right)$ 


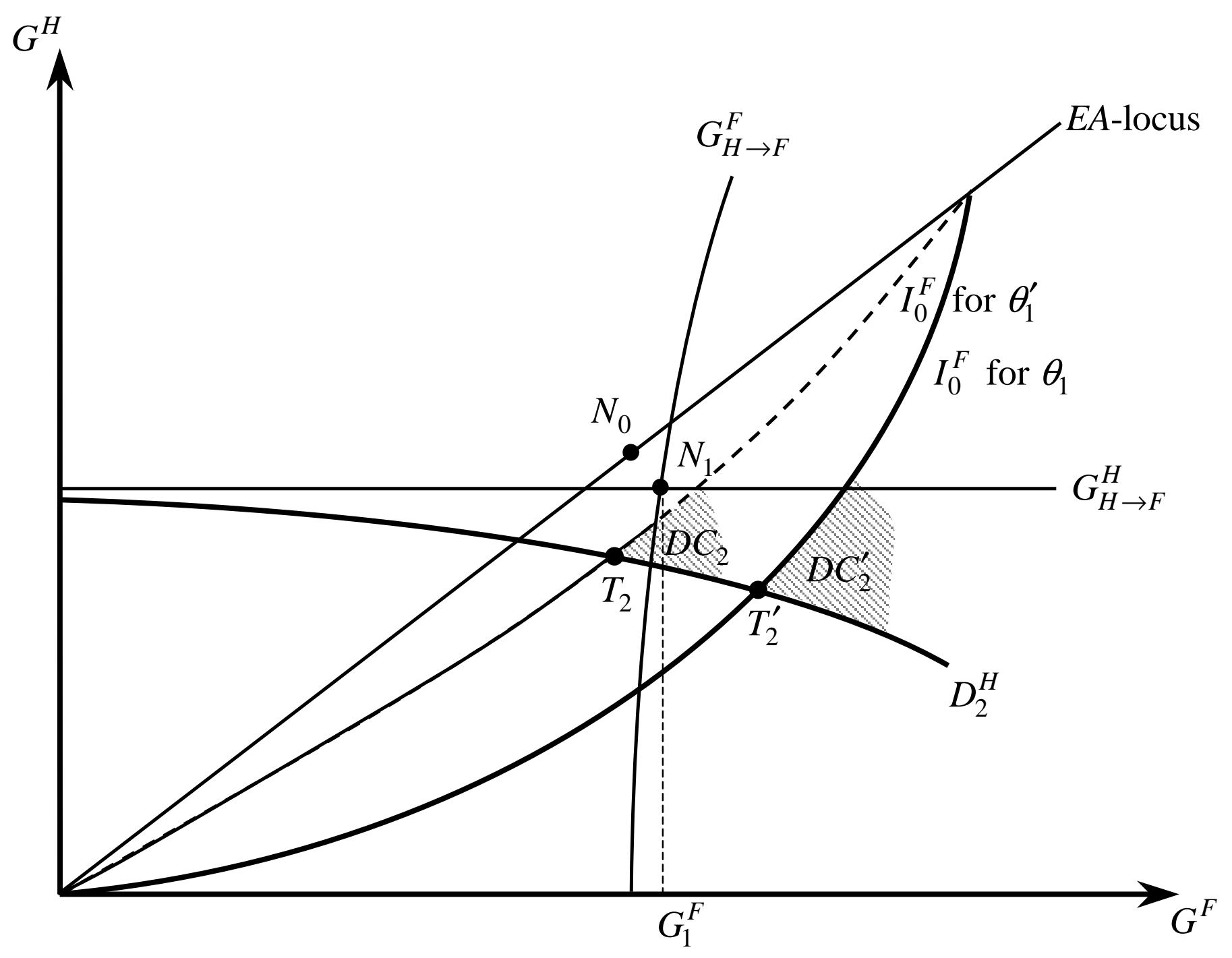

Figure 7. Deviation cones for brain drain reversal $\left(\theta_{1}^{\prime}<\theta_{1}\right)$ 